University of Louisville

ThinkIR: The University of Louisville's Institutional Repository

Electronic Theses and Dissertations

$5-2008$

\title{
Chemical signals as a means of determining health status and selecting mates in humans.
}

Amy M. Cavanaugh

University of Louisville

Follow this and additional works at: https://ir.library.louisville.edu/etd

\section{Recommended Citation}

Cavanaugh, Amy M., "Chemical signals as a means of determining health status and selecting mates in humans." (2008). Electronic Theses and Dissertations. Paper 226.

https://doi.org/10.18297/etd/226

This Doctoral Dissertation is brought to you for free and open access by ThinkIR: The University of Louisville's Institutional Repository. It has been accepted for inclusion in Electronic Theses and Dissertations by an authorized administrator of ThinkIR: The University of Louisville's Institutional Repository. This title appears here courtesy of the author, who has retained all other copyrights. For more information, please contact thinkir@louisville.edu. 
CHEMICAL SIGNALS AS A MEANS OF DETERMINING HEALTH STATUS AND SELECTING MATES IN HUMANS

\author{
By \\ Amy M. Cavanaugh \\ B.A., Drew University, 2002 \\ M.S., University of Louisville, 2005

\begin{abstract}
A Dissertation
Submitted to the Faculty of the

Graduate School of the University of Louisville

in Partial Fulfillment of the Requirements

for the Degree of
\end{abstract}

Doctor of Philosophy

Department of Biology

University of Louisville

Louisville, Kentucky

May 2008 

Copyright 2008 by Amy M. Cavanaugh

All rights reserved 
CHEMICAL SIGNALS AS A MEANS OF DETERMINING HEALTH STATUS AND SELECTING MATES IN HUMANS

\author{
By \\ Amy M. Cavanaugh \\ B.A., Drew University, 2002 \\ M.S., University of Louisville, 2005 \\ A Dissertation Approved on
}

March 31, 2008

by the following Dissertation Committee:

Dissertation Director 


\section{ACKNOWLEDGMENTS}

I would like to express my appreciation to Dr. Lee A. Dugatkin for supporting me throughout this project. Thanks to my committee; Dr. Cynthia Corbitt, Dr. Perri Eason, Dr. Paul Ewald, and Dr. David Westneat, for all their contributions and mentorship. Special thanks to Dr. Ewald for generously lending me the use of his laboratory. Thanks to Lisa Mattingly, Nancy Hansford, and Amber Bacon for helping me at every turn and covering my back more times than I care to admit. My deepest gratitude to Kathy Zinn, whose support, encouragement, and friendship were invaluable. Thanks to Dr. Susanna Remold for all her advice. My thanks to Dr. Trish Sevene-Adams for, among many other things, teaching me to like beer. I am indebted to my fellow Dugatkers, Matthew Druen, Jessica Buckingham, and Dave Mehl for many fruitful conversations and venting sessions. Thanks to Darcie Taggart for Tuesday nights off.

To my parents Joseph and AnnaSue Cavanaugh, thank you for everything; no one could ask for more loving, encouraging parents. Everything I am is because of you. Thanks to my brothers and sisters, Daniel and Alethea Collins-Cavanaugh, Bill and Rebecca Barger, and Matthew Cavanaugh, a small army in their own right who, thankfully, have always been on my side. Thanks to Connor Collins-Cavanaugh and Charlotte Barger for being the most adorable little bundles of indirect fitness anyone could ask for. Thanks to Ranger for always making me smile and laugh and reminding me daily that nothing in this life is as important as taking time to pet the dog. Finally, 
thank you to Alvin Rentsch, for the hugs, for the support, for being my personal champion, for your indefatigable belief in me, and, most of all, for your love. 


\begin{abstract}
CHEMICAL SIGNALS AS A MEANS OF DETERMINING HEALTH STATUS AND SELECTING MATES IN HUMANS
\end{abstract}

Amy M. Cavanaugh

May 10, 2008

The objective of my dissertation research was to determine the role of chemical signals in conveying information regarding an individual's health status and suitability as a mate in humans and to examine the role that commensal microflora play in this system. Chemical signals in humans have been theorized to play a role in disassortative mating relative to the major histocompatibility complex (MHC) and in selection of mates based on fluctuating asymmetry. In addition, chemical signals have been shown to communicate health status in rodents. Commensal microflora are a necessary component of such chemical signaling systems since it is the microflora which ultimately create odor. Results from Chapter 2 and Chapter 3 revealed that, in humans, the axillary microflora are altered during periods of illness. Both a decrease in overall richness of microbes and an increased likelihood of possessing Micrococcus species during or following a period of illness was found. However, these alterations in axillary microflora were not found to result in an altered perception of the scent of men's body odor by 
women (Chapter 3). Results of Chapter 4 found that women in the follicular phase of their cycles prefer the scent of men's body odor whose axillary microflora is most dissimilar to their own. This finding has implications for mechanisms of MHCdisassortative mate selection through olfaction. Taken in total, this work provides evidence that health status can affect the composition of commensal microflora and furthermore that these commensal microflora may convey chemical signals which women could use in mate selection. 


\section{TABLE OF CONTENTS}

\section{PAGE}

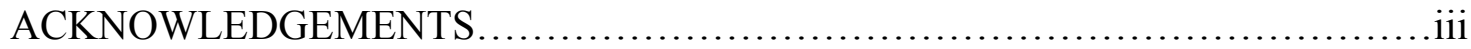

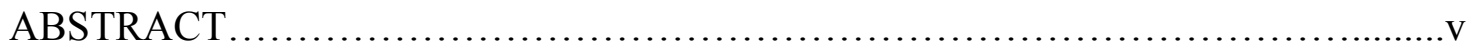

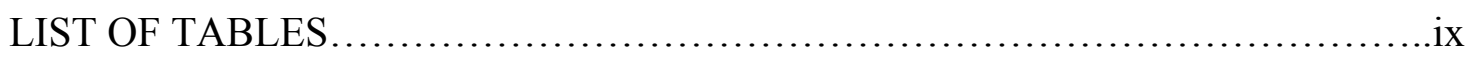

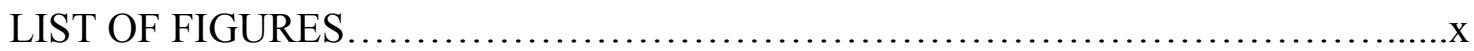

CHAPTER

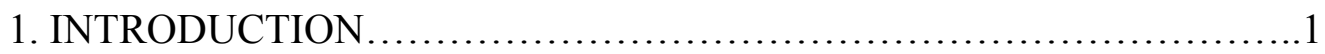

2. DECREASES IN MICROBIAL RICHNESS DURING ILLNESS PROVIDE A MECHANISM FOR CHANGES IN BODY ODOR ......................16

Introduction...................................................... 16

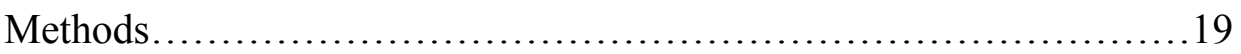

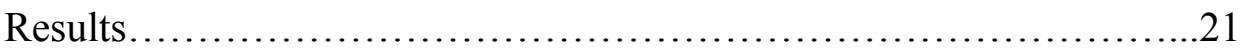

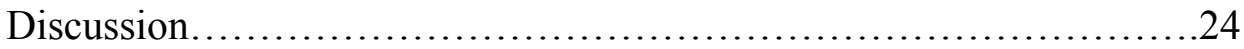

3. ILLNESS AFFECTS COMMENSAL MICROFLORA BUT NOT WOMEN'S PREFERENCE FOR MALE SCENT ......................................27

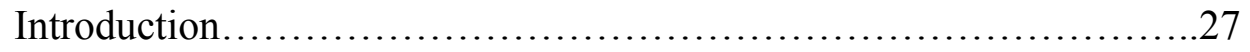

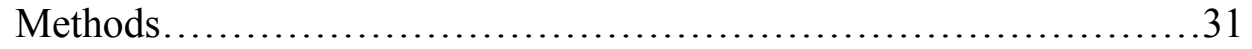

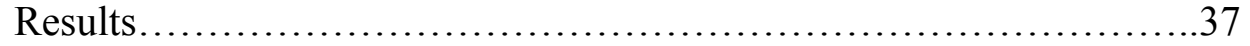

Discussion..................................................... 47

4. SIMILARITY OF COMMENSAL MICROFLORA AFFECTS THE SEXINESS OF MEN'S ODOR ...........................................

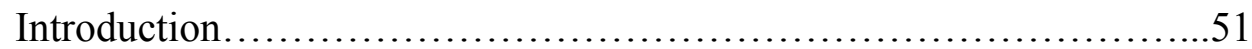

Methods.................................................................

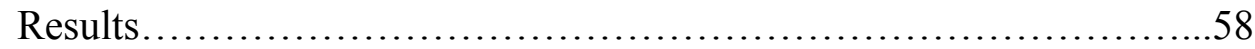

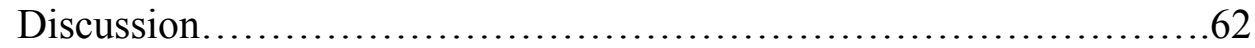

5. SUMMARY AND FUTURE CONSIDERATIONS........................65 
REFERENCES.

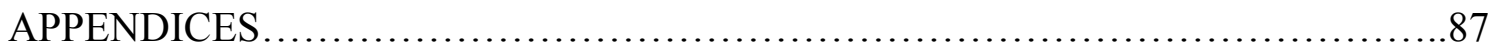

CURRICULUM VITAE ..................................................91 


\section{LIST OF TABLES}

TABLE

PAGE

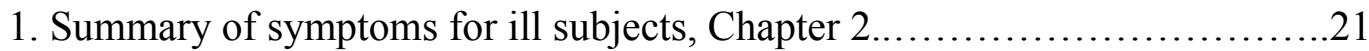

2. Summary of repeated measures ANOVA results........................23

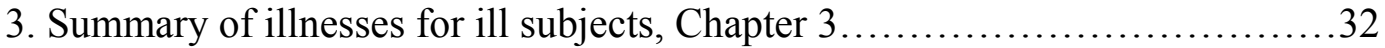

4. Description of menstrual cycle phase assignments......................... 34

5. Description of bacterial groups present on healthy and ill men...............37

6. Description of menstrual cycle phase assignments.......................55 


\section{LIST OF FIGURES}

FIGURE

PAGE

1. Overall density of microflora during periods of health and periods of illness........23

2. Richness of microflora during periods of health and periods of illness...............24

3. Pleasantness ratings of shirts by health.................................. 40

4. Pleasantness ratings of shirts by menstrual cycle phase, Chapter $3 \ldots \ldots \ldots \ldots \ldots \ldots . . .41$

5. Sexiness ratings of shirts by health....................................... 42

6. Sexiness ratings of shirts by menstrual cycle phase, Chapter $3 \ldots \ldots \ldots \ldots \ldots \ldots \ldots . . .43$

7. Intensity ratings of shirts by health...................................... 44

8. Intensity ratings of shirts by menstrual cycle phase, Chapter $3 \ldots \ldots \ldots \ldots \ldots \ldots \ldots . \ldots 45$

9. Overall density of microflora of healthy and ill men.......................... 46

10. Likelihood of Micrococus and Corynebacteria presence in commensal microflora of healthy and ill men.....................................................47

11. Pleasantness ratings of shirts by menstrual cycle phase, Chapter $4 \ldots \ldots \ldots \ldots \ldots \ldots . . . . .58$

12. Sexiness ratings of shirts by women in follicular phase of menstrual cycle by

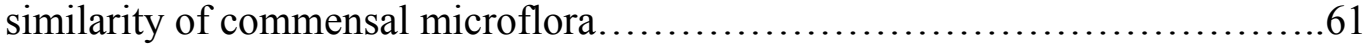

13. Intensity ratings of shirts by menstrual cycle phase, Chapter $4 \ldots \ldots \ldots \ldots \ldots \ldots \ldots 6 . \ldots 6$

14. Mechanisms of illness-induced alterations in body odor.......................66

15. Mechanisms of MHC-derived odor-types................................ 70 


\section{CHAPTER 1}

\section{INTRODUCTION}

Chemical signals are used throughout the living world by bacteria, protists, fungi, plants and animals to facilitate mate attraction and selection (Agosta, 1992). Due to the relative dearth of olfactory receptor cells in the nasal mucosa of humans and other

primates compared to other mammals, humans are believed to be microsomatic, i.e. bad smellers (Kohl et al., 2001). The combination of this alleged microsomatism with our comparative visual acuity has led to the characterization of humans as a visual species (Grammer et al., 2005). However, a growing body of research suggests olfactory communication may play a larger role in human social relationships than previously recognized.

Axillary secretions have been one focus of research on chemical signals in humans. These are the secretions of both the apocrine and eccrine glands located within the axilla, or underarm region. Axillary secretions contain lipocalins which carry chemical signals in a manner analogous to the pheromone systems of other mammals (Wysocki \& Preti, 2004). The secretions also contain a rich mixture of volatile acids (Zeng et al., 1991) as well as steroids that are chemically similar or identical to pheromones in other mammals (Claus \& Alsing, 1976). In addition, several aspects of the location and structure of the axilla increase the likelihood that these secretions will be 
dispersed and received. First, it is an area that normally contains hair. Hair increases the surface area which aids in dispersal of volatiles. Secondly, the axilla is kept warm which aids in volatilization of secretions. Finally, the axilla is relatively close to the nose-level of possible receivers in our bipedal species (Labows, 1988; Wysocki \& Preti, 2004).

While there are many glands present in the axilla, it is the apocrine gland which has drawn the most attention for its potential role in a human pheromone system. This is because the apocrine gland is not stimulated by heat, as are the other glands of the axilla, but rather by pain, fear, and excitement (Labows, 1988;Shelley \& Hurley, 1952). This suggests that rather than functioning to regulate body temperature as the eccrine glands do, the apocrine gland is instead releasing signals in response to changes in an individual's emotional state. The apocrine gland even has characteristics which suggest it could serve as a secondary sexual organ.

A secondary sexual organ is one whose primary purpose is not reproduction per se, but rather procurement of mates (Darwin, 1871). Secondary sexual organs can be identified by sexual dimorphisms in the organ and/or by the delayed development of the organ until puberty (Darwin, 1871). The apocrine gland meets both of these criteria. It is larger in males than in females (Doty, 1985) and it does not develop until puberty and atrophies in post-reproductive individuals (Shelley \& Hurley, 1952).

The vomeronasal organ, the organ responsible for detecting chemical signals in most species, is less functional in humans than in other mamals, which has led many to believe that humans are incapable of detecting chemical signals (Kohl et al., 2001). However, there are several examples of non-human mammals which are able to detect pheromones even when the vomeronasal organ is removed or damaged (Wysocki \& Preti, 
2004; Wysocki et al., 2004). This suggests that other organs, i.e. the main olfactory system, may allow pheromone detection among humans although no conclusive work has been done on this problem. Wysocki \& Preti (2004) have suggested that olfactory neuroepithelium could be responsible for mediating pheromone detection and response in humans.

Indeed, evidence for the human ability to detect and respond to pheromones is quite diverse (Wysocki \& Preti, 2004). Extracts from the male axilla have been shown to increase the regularity of women's menstrual cycles (Cutler et al., 1986), reduce tension and improve mood in women (Jacob et al., 2002a;Preti et al., 2003), and increase how attractive women find male faces (Thorne et al., 2002). Extracts from the axilla and breasts of lactating women have been shown to increase sexual motivation in other women (Spencer et al., 2004). Human sweat may also carry chemical signals of gender and identity (Doty et al., 1978;Russell, 1976), sexual orientation (Martins et al., 2005), ovulation (Kuukasjarvi et al., 2004;Singh \& Bronstad, 2001) human leukocyte antigen (HLA) genotype (Ferstl et al., 1992;Hepper, 1988;Jacob et al., 2002b;Ober et al., 1997; Thornhill et al., 2003;Wedekind \& Füri, 1997;Wedekind et al., 1995) and disease (Brown, 1995;Liddell, 1976).

This last function of human pheromones, the ability to determine an individual's health status prior to mating with them could be beneficial for two reasons. First, by determining that a conspecific is ill before coming into close contact with them for mating purposes, an individual can reduce their likelihood of contracting a contagious disease. This is the contagion indicator hypothesis suggested by Able (1996). Specifically, Able predicts that females should inspect male traits whose expression could 
indicate the presence and/or intensity of "associatively transmittable" parasites. By choosing to avoid males who are contagious, she reduces her risk of acquiring parasites and, where paternal care exists, she reduces the risk of her offspring becoming infected by their father.

Second, a female may secure good genes for her offspring if she chooses to mate only with males who demonstrate genetic disease resistance (Hamilton \& Zuk, 1982). "Good genes" may fall into three categories: genes that increase the likelihood of survival of offspring, genes that increase the likelihood of reproduction for offspring, and genes that are complementary to the females' (Trivers, 1972). When females determine which males have good genes by inspecting traits whose expression depends on health and vitality, then genes which confer genetic resistance could be considered "good" in all three categories. By providing resistance to disease, these genes are probably increasing the likelihood of survival. Since individuals who are able to signal their health are more likely to be chosen as mates, then the genes for disease resistance will also increase the likelihood that the bearers of these genes will reproduce. Finally, in populations challenged by rapidly evolving parasites or multiple parasites, the best genes for disease resistance in a mate will be those which are complementary to the female's, as opposed to redundant with the female's, thus ensuring the largest immune arsenal possible for the offspring.

Both of these hypotheses to explain selective mating with healthy males are essentially derivatives of the handicap principle (Zahavi, 1975, 1977). According to Zahavi $(1975,1977)$, both the development and the maintenance of secondary sexual characters may serve as a signal of quality in terms of genetic resistance even as they 
pose a significant handicap to survival. He describes this handicap as a test of quality. Any male which possesses a well-developed secondary sexual character has passed this test. While males without the character may actually be of better quality, the female cannot know this, since the male without the character has not been tested. Anytime the risk of choosing an untested male outweighs the cost imposed by the test, females should choose to mate only with males who possess the proper certificate, the well-developed secondary sexual character. Furthermore, in order for these characters to serve as honest signals of a male's quality, they must be costly to produce and maintain. Otherwise, any male could claim to have taken and passed the test, even though he did not. In fact, male secondary sexual characters are well-suited to serve as honest signals of disease resistance and disease state. In most species, high testosterone levels are required to develop and maintain these characters (Folstad \& Karter, 1992) however testosterone is immunosuppressive. Males will only be able to fully develop these exaggerated characters if they are not suffering from a chronic or incident infection or if their immune system is so strong that it can resist infection even while partially suppressed (Folstad \& Karter, 1992).

Evidence that visual and acoustic sexual characters respond negatively to infection and serve as a basis for female choice of mates is widespread and abundant (Clayton, 1991;McLennan \& Brooks, 1991;Møller, 1994;Read, 1990;Zuk, 1992;Zuk et al., 1990). In humans, a study of 29 cultures found that physical attractiveness was valued in a mate more in geographical areas with greater pathogen prevalence (Gangestad \& Buss, 1993). This study assumed attractiveness as a proxy for physical traits that are associated with pathogen resistance. Specific evidence for the contagion indicator 
hypothesis was found by Jones and colleagues (2005). Women were most attracted to apparently healthy faces in the luteal phase of their menstrual cycles and when they were pregnant. These are times when progesterone, another immunosuppressive hormone, is highest and women should thus be most concerned with avoiding contagious individuals. Another measure of an individual's health history, symmetry, has been found to be the subject of sexual selection in humans. Symmetry is often used as a measure of developmental stability. Small deviations from bilateral symmetry which fluctuate across generations, also known as fluctuating asymmetry, occur as a result of an individual's inability to properly implement a developmental program when challenged by a developmental stress (Møller \& Swaddle, 1998). Developmental stress may be due to genetics, i.e. inbreeding, homozygosity, and hybridization, or environmental factors. Environmental factors can include abnormal temperatures, malnutrition, unpredictability of food sources, chemical pollution, noise pollution, high population density and parasitic infection (Møller \& Swaddle, 1998).

Disease and malnutrition are the major external biotic factors which can be considered developmental stressors in humans (Vander et al., 1986). Because it covaries negatively with many measures of fitness in many species, including humans, fluctuating asymmetry is considered a useful measure of genetic quality (Polak \& Trivers, 1994; Thornhill \& Møller, 1997). In so much as disease can increase fluctuating asymmetry, selecting for symmetric mates is one way to select for genetically diseaseresistant mates. Both men and women seem to prefer symmetry in their partners. Men and women prefer symmetric to asymmetric faces (Grammer \& Thornhill, 1994). Men prefer women with symmetric bodies to women with asymmetric bodies (Tovée et al., 
2000). Women with more symmetrical partners have more orgasms during sexual intercourse (Thornhill et al., 1995). In addition, it seems that information pertaining to symmetry may be contained in chemical signals. Males found the body odor of women that they deemed more attractive as more pleasant, even though they did not know the identity of the odor donors (Rikowski \& Grammer, 1999). During their period of highest fertility, women prefer the scent of more symmetrical men (Rikowski \& Grammer, 1999; Thornhill \& Gangestad, 1999; Thornhill et al., 2003). Women also preferred the scent of men they had independently deemed attractive (Rikowski \& Grammer, 1999).

But what of chemical signals as sexual characters that may respond negatively to infection? Penn and Potts (1998b) suggest that chemical signals would be particularly effective indicators of an individual's health status because they are direct and often more labile than morphological traits. In addition, the fact that chemical signals are so widely used in mate attraction and selection (Agosta, 1992) suggests a potentially long history of parasite-mediated sexual selection.

Several studies in mice have shown that females use odor as a means of examining a male's health history. Estrous females display reduced interest in the odors of males infected with a protozoan parasite (Kavaliers et al., 1997). While all infected males were less attractive than healthy males, females found the contagious males least attractive suggesting support for the contagion indicatory hypothesis. Influenza infection also decreased the attractiveness of male urine to females (Penn et al., 1998). Mouse mammary tumor virus, whether obtained environmentally or genetically transmitted, altered the body odor of mice in both males and females (Yamazaki et al., 2002). Regardless of the presence or absence of tumors, mice were able to distinguish between 
the odors of both environmentally and genetically infected mice. This supports the Hamilton and Zuk (1982) theory of parasite-mediated sexual selection. Finally, male mice challenged with a non-replicating strain of Salmonella deposited scent marks less frequently than non-challenged males and the scent marks left by these males were less attractive to females (Zala et al., 2004). Since the bacterium used was non-replicating, the infection-induced alteration in odor was due to activation of the immune system rather than a pathological by-product of disease.

In humans, physicians have long recognized that body odor could be used to diagnose certain diseases (Penn \& Potts, 1998b). Smallpox, typhoid, diphtheria, yellow fever, tuberculosis, gingivitis, herpes, syphilis, gangrene, hyperhidrosis, infected eczema, bacterial vaginosis, lice, infected ulcers, abscesses, scurvy, diabetic ketosis, gout, schizophrenia, phenylketonuria, defective metabolism of amino acids, hyperaminoaciduria, and the inability to metabolize butyric and hexanoic acids have all been recognized to lend an offensive and/or distinctive odor to sweat and other body secretions (Brown, 1995;Liddell, 1976). Indeed, these changes in body odor are so reliable as markers of these specific diseases that technological devices, so-called "electronic noses", are being developed to aid in the diagnosis of disease from sweat, breath, and urine (Penn \& Potts, 1998b). These diseases represent those that have such a dramatic effect on body odor that observers are conscious of the difference. However, a chemical signal does not have to be perceived consciously to have an effect. Kohl et al. (2001) point out that most chemical signals elicit a response from the receiver without triggering cognitive processing. 
It seems that signs of disease and infection are universally found to be sexually unattractive to humans (Penn \& Potts, 1998b). The emotion of disgust itself, one of the six basic emotions described by Darwin (1872), may function to keep individuals away from sources of contagion (Nesse \& Williams, 1995;Pinker, 1998). Indeed a crosscultural study found that disgust elicitors fell into five broad categories: bodily excretions and body parts, decay and spoiled food, particular animals, certain categories of people, and violations of morality or social norms (Curtis \& Biran, 2001). Further analysis of these categories shows that the underlying disgust elicitor is related to contagion in four out of five of these categories. Specifically bodily excretions and body parts associated with disease, spoiled food, animals known to carry disease, and people perceived as being ill were universally disgusting. This list of stimuli was generated by surveying individuals so it does not rule out the possibility that the odors associated with these items would be just as likely to elicit a disgust response as a visual stimulus. Indeed, though the difference was not significant, due at least in part to small sample sizes, a tendency for women to find the scent of ill men less attractive than other men's scent has been found (Thornhill et al., 2003).

What might account for the changes in body odor that accompany illness? According to Penn \& Potts (1998b) there are four possibilities. First, the composition of commensal microbes which strongly contribute to body odor may be changed. Second, upregulation of the genes of the major histocompatibility complex might affect odor since MHC has been shown to regulate odor (see below). Third, activation of the immune system may alter the excretion of volatile acids from the body, such as those identified by Zeng and his colleagues (1991)(Zeng et al., 1991). It has been shown that the 
composition of volatile acids in body fluids is altered during an infection due to the activity of the infecting pathogen (Edman \& Brooks, 1983), although sweat was not one of the body fluids analyzed. Fourth, activation of the immune system may alter the excretion of metabolic by-products from the endocrine system such as the steroids androstenone and androstenol found by Claus \& Alsing (1976) and Froebe and colleagues (1990). This is most likely due to the fact that androgens such as these are immunosuppressive, so during an infection, an individual would be expected to decrease androgen production in order to reallocate resources to the immune response.

None of these hypotheses has been thoroughly examined. The commensal microflora hypothesis seems the most supported by current evidence, however, as axillary secretions are entirely odorless until acted on by the commensal bacteria of the skin (Shelley et al., 1953). Indeed, the volatile acids and endocrine metabolites mentioned by Penn \& Potts (1998b) do not create an odor until liberated by bacterial enzymes (Froebe et al., 1990;Natsch et al., 2003;Zeng et al., 1992) and no significant differences in the amount or composition of lipids in secretions have been found between people with different body odors (Leyden et al., 1981). Ill individuals have been shown to posses different microfloral communities than healthy controls (Larson et al., 1986). However, this was a study of hospitalized individuals in comparison with healthy adults from a university population. Therefore, it is possible that these differences were due not to the health of the subjects, but rather due to an interaction of their health and location. It is well known that hospitals are breeding grounds for the kinds of antimicrobic resistant skin flora which were found on the ill subjects. Further work still needs to be done to 
determine if differences in the skin flora of ill vs. healthy individuals exists without the confounding factor of hospitalization.

Different microbial groups have also been shown to create different odors. Axillary microflora are composed of Coryneforms, Micrococci, Propionibacteria and occasional gram negative rods (Leyden et al., 1981). Propionibacteria most likely do not contribute to body odor as they reside deep in the recesses of the sebaceous follicles. If they were involved in body odor, the apocrine sweat should be odorous by the time it reaches the surface and it is not (Leyden et al., 1981). Coryneforms give a typical musky body odor while Micrococci give a sweaty acid odor (Leyden et al., 1981). Gram negative rods contribute easily distinguishable but not easily describable odor that is distinct from the odor of Coryneforms and Micrococci (Leyden et al., 1981). Typically, individuals will posses either a Coryneform or Micrococci dominated flora. However differential sensitivity to lysozymes in eccrine sweat may alter the community (Jackman \& Noble, 1983). It has not been demonstrated yet, but perhaps this is a mechanism by which activation of the immune system could alter the microbial community of the skin. Since lysozymes facilitate phagocytosis of the bacterial cells by white blood cells, perhaps lysozyme concentrations are increased in eccrine secretions during immune system activation in order to facilitate macrophage activity. If either Corynebacteria or Micrococci are more sensitive to lysozymes, this could explain an alteration in the commensal microbial community during illness.

Perhaps the most heavily researched area of chemical signaling in humans has been in relation to the major histocompatibility complex (MHC). The MHC is a collection of highly polymorphic loci that control the immune's system recognition of 
self and non-self. The class I and II MHC genes encode cell-surface glycoproteins. These MHC molecules present small peptide antigens to T-cells. Thus, they control both cell- and antibody-mediated specific immune responses (Apanius et al., 1997). MHC genes are the most polymorphic coding loci known in vertebrates. Two possible explanations for these polymorphisms are selection from parasites and disassortative mating preferences (Apanius et al., 1997;Penn \& Potts, 1999). Evidence for disassortative mating has been found in mice, salmon, and humans.

While laboratory experiments with mice have not shown disassortative mate choices based on MHC-type, semi-natural experiments have shown this pattern (Manning et al., 1992). In this experiment, due to mate selection, the wild population of females produced more MHC heterozygous offspring than expected by chance. Atlantic salmon appear to choose their mates in order to increase the heterozygosity of their offspring at the peptide-binding region of the MHC (Landry et al., 2001). Among the Hutterites, a North American reproductively isolated group of European ancestry, it was found that the likelihood of married couples sharing MHC alleles was significantly different from chance (Ober et al., 1997). This study took population structure into account. Other studies which have not taken population structure into account or did not examine extramarital copulations did not find a disassortative pattern with respect to MHC-type (Hedrick \& Black, 1997; Ihara et al., 2000).

It appears that this distinction is mediated by chemical signals, however the question remains how a complex of genes whose primary role is ostensibly to prevent infection might also be influencing body odor. Four hypotheses have been suggested (Penn \& Potts, 1998a). The first of these is the MHC molecule hypothesis. According to 
this hypothesis, it is the MHC molecules, or fragments thereof, which are themselves providing the odorants. This hypothesis was suggested because MHC molecules and fragments have been found both in mouse urine (Singh et al., 1987) and human sweat (Wysocki \& Preti, 2004). However, this explanation seems unlikely for two reasons. First MHC molecules are nonvolatile proteins and thus not odorous (Penn \& Potts, 1998a). Second, removal of MHC proteins from the urine of rats did not remove the signal of individuality (Brown \& Schellinck, 1992;Singer et al., 1993) and rats were not able to discriminate individuals based on the odors of purified MHC molecules (Brown et al., 1987).

The second hypothesis is the carrier hypothesis. This hypothesis states that as MHC molecules degrade they are converted from peptide-presenting structures into volatile-transporting molecules which pick up volatile aromatics produced by commensal flora and transporting them to the urine or sweat (Pearse-Pratt et al., 1992). This hypothesis requires that MHC molecules be converted from hydrophilic, peptide-binding molecules to hydrophobic, aromatic-binding molecules as they degrade which seems highly unlikely (Penn \& Potts, 1998a).

A third hypothesis, the microflora hypothesis, suggests that MHC genes shape the microbial flora in an allele-specific fashion and it is these bacteria which produce the odorants (Penn \& Potts, 1998a). Rats that have been raised in a germ-free environment are no longer distinguishable to other rats. Once these rats were returned to normal housing, and the commensal microflora therein, they were discriminable (Singh et al., 1990). In addition, treating rats with antibacterial agents altered the maternal odors as well as body odors of adult males (Brown \& Schellinck, 1992). While mice have been 
able to discriminate the odors of germ-free raised mice (Yamazaki et al., 1990), rats have not been able to distinguish between two different MHC strains of germ-free raised mice (Schellinck et al., 1995). While it is not entirely clear why this difference exists between rats and mice, it has been suggested that the discrimination made by rats was an artifact of the training procedures they are subjected to (Penn \& Potts, 1998a).

A final hypothesis, the peptide-microflora hypothesis, combines a variant of the carrier hypothesis with the microflora hypothesis. According to the peptide-microflora hypothesis, MHC molecules bind to allele-specific proteins (Falk et al., 1991) which are later volatilized to provide the odorant (Singer et al., 1997). Furthermore, it is the commensal microflora which are suggested to convert these proteinaceous pre-cursors into volatile odorants. It has been shown that bacteria are required to hydrolyze the precursors of axillary odorants in humans (Froebe et al., 1990;Natsch et al., 2003;Zeng et al., 1992). However the carrier molecule for at least the main axillary odorant, methylhexenoic acid, has been identified as apolipoprotein $\mathrm{D}$, a member of the lipocalins family (Zeng et al., 1996). An analysis of the volatile components of male mouse urine showed that the difference in odortype between MHC dissimilar mice was due to a difference in the relative amounts of acids, rather by compounds that are unique to a specific MHCtype (Singer et al., 1997). Perhaps the other acid pre-cursors contributing to the odor are carried by MHC molecules or MHC somehow affects the availability of the various lipocalins, but this is still unknown.

The goal of my dissertation research was to examine several aspects of the interaction between commensal microbes and body odor in humans, focusing specifically on the ways body odor may act as a chemical signal during mate selection. My 
hypothesis was that body odor, as determined by commensal microbes, could provide cues to a person's current health status, and potentially an indirect cue to their MHC genotype, which would allow individuals to take these factors into account when selecting a mate. I conducted three experiments. The first was a longitudinal study which examined the response of the axillary microflora to acute illnesses in humans. The second study examined the differences between the communities of axillary microflora in healthy and ill men and also examined how attractive women found the body odor of these men. The third study examined how attractive women found the body odor of men as a function of how similar the community of axillary microflora of each man was to the woman who was rating his odor, an indirect test of the commensal microflora hypothesis for MHC scent preferences. All three experiments were examined and approved by the University of Louisville Institutional Review Board under protocol numbers 281.05, 082.07, and 083.07 respectively. 


\section{CHAPTER 2}

\section{DECREASES IN MICROBIAL RICHNESS DURING ILLNESS PROVIDE A MECHANISM FOR CHANGES IN BODY ODOR.}

\section{Introduction}

According to Hamilton and Zuk's theory of parasite-mediated sexual selection, females should choose to mate with males who are disease resistant (Hamilton \& Zuk, 1982). This decision should be based on scrutiny of traits known to respond negatively to infection. There are several possible benefits that females may gain by avoiding infected males as mates: for example, avoiding contracting the infection herself and/or producing offspring with superior disease resistance, if resistance is heritable (Apanius et al., 1997;Moore, 2002). In addition, in species with paternal care, females which choose healthy males as mates are more likely to obtain superior parental investment for their offspring (Moore, 2002). Numerous studies of visual and acoustic signals have found that these sexual traits can reliably indicate a male's resistance to parasites (see reviews in (Clayton, 1991;McLennan \& Brooks, 1991;Møller, 1994;Read, 1990;Zuk, 1992)).

In the past decade, interest in the role of health in mediating chemical signals between the sexes has increased (Moore, 2002). Chemical signals are prevalent throughout the animal kingdom, indeed even across domains, allowing for a broader range of comparative studies, and such signals are direct and often more flexible than 
morphological traits which makes them ideally suited to communicate health status (Penn \& Potts, 1998b). Much of the work concerning chemical signals has focused on mice. The odor of males infected with nematodes (Kavaliers et al., 2003), Salmonella (Zala et al., 2004), protozoan parasites (Kavaliers et al., 1997), influenza (Penn et al., 1998) or mouse mammary tumor virus (Yamazaki et al., 2002) were all either unattractive or repellent to female mice. Yamazaki's work using mouse mammary tumor virus as the infectious agent found that even when odor preference tests were done after infecting males with the virus but before any physiological symptoms were evident, females preferred the odor of uninfected males. The fact that females were still able to discriminate between the odors of healthy males and ill males who nonetheless appeared healthy, and found the odor of those ill males aversive indicates the strength of chemical signals as honest signals of health. In addition, this suggests that females should rely more heavily on chemical signals because the ability to discriminate between the odors of healthy and infected males before visual or behavioral symptoms are evident would provide females an earlier, or additional, warning that a potential mate was not suitable.

Because humans lack a vomeronasal organ, but do possess relatively strong eyesight, it has been assumed that humans rely primarily on visual cues and pay little attention to, indeed may be fairly incapable of detecting, chemical signals. However, in the past decade, numerous studies have shown that humans are capable of discriminating between body odors of individuals (Ferstl et al., 1992;Thornhill \& Gangestad, 1999; Thornhill et al., 2003; Wedekind \& Füri, 1997;Wedekind et al., 1995). To date, women have been found to prefer the scent of men with dissimilar MHC types, as well as men with relatively low fluctuating asymmetry. It has been suggested that by preferring 
the scent of MHC dissimilar men, women may be selecting for increased heterozygosity of their offspring's immune genes, or avoiding inbreeding (Apanius et al., 1997). Low fluctuating asymmetry may be preferred because it indicates men with good genes that allowed them to withstand developmental challenges and still invest enough energy to maintain symmetry (Møller \& Swaddle, 1998).

But is it possible for humans to distinguish a potential mate's health status through body odor? A variety of illnesses, including but not limited to smallpox, typhoid, yellow fever, diabetes, and schizophrenia, are known to cause changes in a person's body odor (Brown, 1995;Liddell, 1976). In addition, Thornhill and Gangestad (2003) found evidence to suggest that women may find the body odor of ill men less attractive than the body odor of healthy men, but specific illnesses were not recorded in this study.

Three possible mechanisms for illness-related changes in body odor have been suggested (Penn \& Potts, 1998b). First, illness may cause metabolic changes that affect the secretions which eventually give rise to body odor (Edman \& Brooks, 1983). Second, since expression of MHC genes is upregulated during illness, the effect that these genes normally have on body odor may be altered, thus altering the odor (Kavaliers \& Colwell, 1995a, b). Finally, the community of commensal microflora that normally inhabits the skin may be altered during illness (Penn \& Potts, 1998b).

It has long been known that commensal microbes are a key component for body odor. A series of experiments in the 1950's conclusively demonstrated that human sweat is entirely odorless until it is acted on by the bacteria that inhabit the skin of the axilla (Shelley et al., 1953). In addition, body odor of individuals changes as a result of which 
bacteria are present in the axilla (Leyden et al., 1981). While it is unlikely that bacteria causing infections of the respiratory tract, for example, would also take up residence on axillary skin, it is possible that an immunochallenged body will not be able to regulate the normal skin microflora as well as a healthy one. My hypothesis was that the community of commensal microbes would be altered from its normal state when a person was ill.

\section{Methods}

Thirty-nine volunteers were recruited from the University of Louisville. Subjects were recruited via word of mouth, either personal communication with me or with friends and colleagues familiar with my study, and flyers posted around the campus of the University of Louisville (see Appendix 1). All subjects (24 female, 15 male) were between the ages of 18-41, and reported being free of any chronic illnesses. I took three samples from each subject with six weeks in between sampling periods. Prior to each sampling, subjects were asked to refrain from showering or wearing deodorant for 24 hours. In each sample period, subjects were asked to describe their health throughout the past six weeks. Any subjects who reported being ill during the previous six weeks (or currently) were labeled as ill for the purposes of our analysis. Subjects' self-reported symptoms are listed in Table 1. My method of classifying subjects' health status is a conservative measure as individuals who had suffered only minor illness several weeks before the sampling would be included with individuals who were suffering more serious illnesses on the day of the sampling. Thus the potential effect of illness on the axillary microflora would be diluted by including these individuals. 
A sample of the community of commensal microbes was taken from one axilla of each subject during each visit by swabbing a $25 \mathrm{~cm}^{2}$ area with a cotton swab that had been soaked in sterile saline. I then inoculated $10 \mathrm{ml}$ of sterile nutrient broth with the swab. Cultures were incubated for 24 hours at $37^{\circ} \mathrm{C}$ and then serially diluted and counted using a standard plate count technique. Previous surveys of axillary microflora have identified the bacteria present across a diverse sample of humans (Leyden et al., 1981). The vast majority of bacteria in the axilla are gram positive and fall into four taxa: the Corynebacteria, the Brevibacteria, Micrococci, and Staphylococci. The remaining organisms are gram negative and are relatively rare. Each of these five groups has been identified with a specific odortype. Corynebacteria and Brevibacteria contribute a "pungent, unpleasant odor." Micrococci and gram negatives contribute a "distinctive sweaty, acid odor." Staphylococci and gram negatives contribute "odors of a different quality, easily distinguishable from classic body odor" (Leyden et al., 1981). Because odortypes were attributed to larger groups of bacteria, as opposed to different odors being attributed on a species by species basis, I limited my identification to these five larger groups.

The organisms present in each sample were identified to the genus level (for gram positive species) following Bergey's Manual of Determinative Microbiology. A gram stain was used to identify bacteria as either gram positive or gram negative. In addition, visualization of the stained bacteria allowed me to determine whether gram positive organisms were rod-shaped (Corynebacteria or Brevibacteria) or cocci (Micrococcus or Staphylococcus). I was able to distinguish between the gram positive rods using a gelatinase test. Corynebacteria are gelatinase negative while Brevibacteria are gelatinase 
positive. I distinguished between the gram positive cocci by challenging them with the antibiotic bacitracin. Staphylococcus are resistant to bacitracin but Micrococcus are susceptible.

For the first 12 subjects (nine female, three male) I only recorded presence/absence data for each taxon. Therefore these samples could only be included in the analysis of richness (see below) but not the analysis of density. I calculated both overall densities of microorganisms for each sample from the remaining 27 subjects as well as richness of microflora. Richness was calculated as the total number of the larger groups (described above) present in the sample. To analyze the effect of health status on density of axillary microflora, I used a repeated measures ANOVA. I used a square root transform on the density of bacteria to meet the assumptions of the model (Gotelli \& Ellison, 2004). I also used a repeated measures ANOVA to analyze the effect of health status on richness of axillary microflora. In addition, I ran a separate repeated measures ANOVA to analyze the effect of health status on density of each taxon. All stastistical analyses were run using the MIXED procedure provided by SAS. This procedure employs maximum likelihood estimates and does not require balanced data within subjects as with the GLM procedure (Wolfinger \& Chang, 1995).

\section{Results}

Health status did not have a significant effect on the overall density of axillary microflora (ANOVA $F_{1,65.6}=0, p=0.87$ ). Individuals maintained a similar density of microorganisms when they were healthy as when they were ill (Fig. 1). Subject sex was initially included in the analysis, however it was not significant $\left(\right.$ ANOVA $_{1,25.2}=2.07 \mathrm{P}$ 
$=0.16)$ so it was dropped from the model. In addition, there was no significant difference in the density of any one taxon when an individual was ill and when they were healthy (Table 2).

Health status did have a significant effect on the richness of the axillary microflora (ANOVA $\left.F_{1,111}=6.61, p=0.01\right)$. Individuals experienced a decline in richness of microbes present when they were ill compared to when they were healthy (Fig. 2). As with the analysis of density, subject sex was dropped from the model after it was found to be non-significant (ANOVA $\mathrm{F}_{1,54.7}=0.76, \mathrm{P}=0.39$.)

Table 1. Self-described symptoms of subjects who reported being ill during the course of the study. Twenty-nine subjects reported being ill at least once; most reported multiple symptoms.

\begin{tabular}{|c|c|}
\hline Symptom & $\begin{array}{c}\text { Number of Subjects } \\
\text { Reporting }\end{array}$ \\
\hline Congestion & 23 \\
\hline Headache & 8 \\
\hline Sore Throat & 13 \\
\hline Lethargy & 4 \\
\hline Coughing & 12 \\
\hline Runny Nose & 7 \\
\hline Fever & 8 \\
\hline Body Aches & 4 \\
\hline Nausea & 4 \\
\hline Diarrhea & 2 \\
\hline Dizziness & 1 \\
\hline
\end{tabular}


Table 2. ANOVA tables for all repeated measures analyses of the effects of health on axillary microflora.

\begin{tabular}{|c|c|c|c|c|}
\hline Test & $\begin{array}{c}\text { Numerator } \\
\text { DF }\end{array}$ & $\begin{array}{c}\text { Denominator } \\
\text { DF }\end{array}$ & $\begin{array}{c}\text { F- } \\
\text { value }\end{array}$ & $\begin{array}{c}\text { p- } \\
\text { value }\end{array}$ \\
\hline $\begin{array}{c}\text { Overall } \\
\text { Density }\end{array}$ & 1 & 65.6 & 0.03 & 0.87 \\
\hline Gram Negative & 1 & 75.5 & 2.64 & 0.11 \\
\hline Corynebacteria & 1 & 76 & 1.38 & 0.24 \\
\hline Brevibacteria & 1 & 57 & 0.1 & 0.76 \\
\hline Staphylococcus & 1 & 73.1 & 0.83 & 0.36 \\
\hline Micrococcus & 1 & 70.8 & 0.08 & 0.78 \\
\hline Richness & 1 & 111 & 6.61 & 0.01 \\
\hline
\end{tabular}

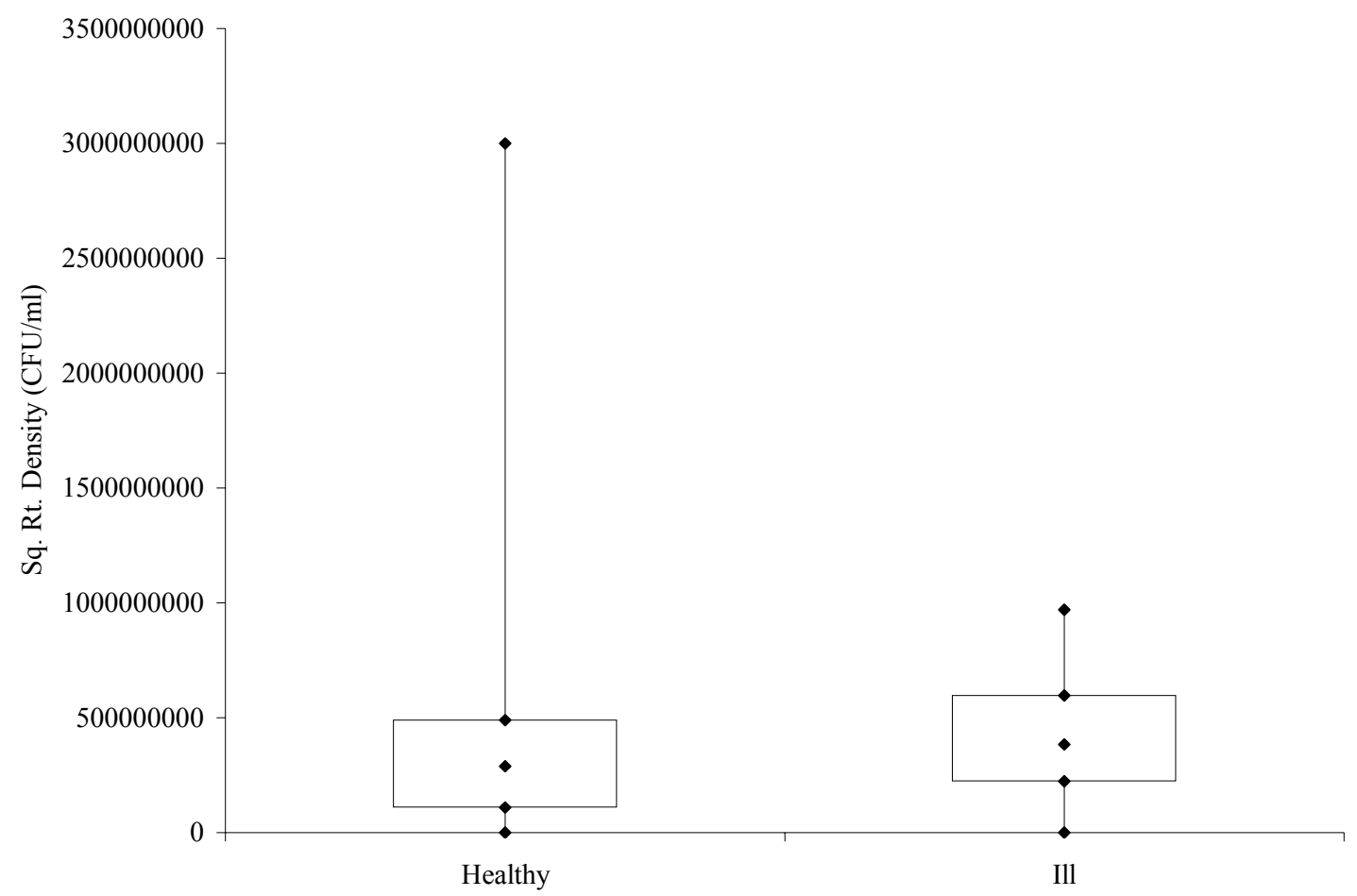

Figure 1. Effect of health status on density of axillary microflora. There is no significant difference in the density of axillary microflora of individuals when they are healthy and when they are ill (Repeated measures ANOVA $F_{1,65.6}=0, p=0.87$ ). 


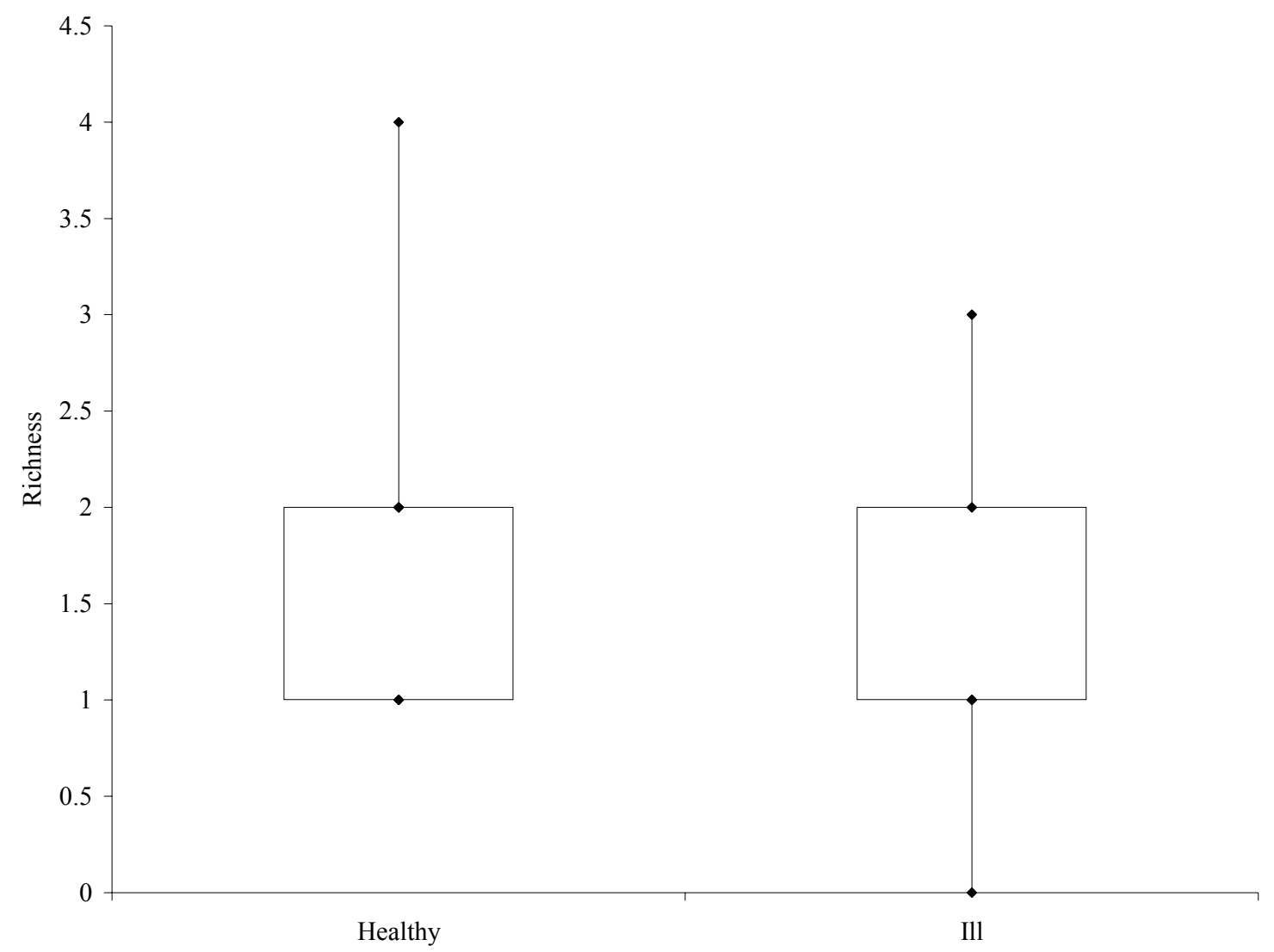

Figure 2. The effect of health status on diversity of axillary microflora. Individuals maintained a higher diversity of taxa (Mean $\pm \mathrm{SE}=1.79 \pm 0.08, \mathrm{n}=76$ samples $)$ when healthy than when ill (Mean $\pm \mathrm{SE}=1.43 \pm 0.11, \mathrm{n}=37$ samples). The difference is significant (Repeated measures ANOVA $F_{1,111}=6.61, \mathrm{P}=0.01$ ).

\section{Discussion}

The purpose of this study was to determine whether the community of axillary microflora is altered during, or following, a period of illness. My results suggest that illness does affect the community of commensal microbes that is responsible for 
generating body odor. Individuals experienced a reduction in the diversity of bacteria that were present in their axillae while they were ill as compared to when they were healthy. This change was not due to an overall decrease in the number of bacteria present as there was no change in the overall density of microorganisms following or during a period of illness. It is possible that activation of the immune system causes energy to be shifted away from maintaining homeostasis of commensal microflora such that one group is able to dominate. It was not possible in this study to determine how long it would take the commensal microflora to return to a normal state after a period of illness. Future studies should use more frequent sampling in order to examine this.

This decrease in microbial diversity during or following a period of illness has interesting implications for the generation of odor and even mate attraction. Perhaps the offensive odors that have previously been associated with illness in humans may be due to one taxon dominating the broader axillary community. It is possible that odors attributed to illness may be due to one odor overpowering a usually more balanced bouquet. Alternatively, a less diverse community of microflora may deliver an incomplete signal which is thus perceived as less attractive than the complete signal released by the more diverse community of a healthy man's axilla. Or, perhaps one type of bacteria e.g. Micrococcus, dominate the flora during times of illness and it is the odor of this bacteria which signals ill health.

It is important to note that I have not yet established that this change in the axillary community does actually result in a change in body odor. Nor have I determined whether there is a systematic change in the taxa present. The work described in Chapter 3 was conducted in order to establish more specifically the manner in which the 
microflora is changed as well as possible impacts of these changes on body odor and even mate selection. 


\section{CHAPTER 3}

\section{ILLNESS AFFECTS COMMENSAL MICROFLORA BUT NOT WOMEN'S PREFERENCE FOR MEN'S SCENT.}

\section{Introduction}

Animals may use chemical signals to gather a wide variety of information about others and the environment including identity, territory boundaries, predator detection, and sexual receptivity (Agosta, 1992;Brennan \& Kendrick, 2006;Brennan \& Zufall, 2006). In addition, a growing body of evidence suggests that chemical signals in the form of body odor may contain cues to an individual's health status.

Several studies have found that a variety of infections alter the odor of male mice. When males were infected with a protozoan parasite, estrous females displayed reduced interest in the chemical markings of such males (Kavaliers et al., 1997). Influenza infection also decreased the attractiveness of male urine to females (Penn et al., 1998). Mouse mammary tumor virus, whether obtained environmentally or genetically transmitted, altered the body odor of mice in both males and females (Yamazaki et al., 2002). The alteration was perceptible by the mice regardless of the presence or absence of tumors. Finally, male mice challenged with a non-replicating strain of Salmonella deposited scent marks less frequently than non-challenged males and the scent marks left by these males were less attractive to females (Zala et al., 2004). In all of these studies, 
not only did infection alter the odor of the mice, this change in odor rendered the infected mice less attractive as potential mates.

Humans too experience changes in body odor as a result of a variety of illnesses. Doctors have long recognized that body odor could aid in the diagnosis of certain diseases (Penn \& Potts, 1998b). Diseases as varied as smallpox, typhoid, diphtheria, yellow fever, tuberculosis, gingivitis, herpes, syphilis, gangrene, hyperhidrosis, infected eczema, bacterial vaginosis, lice, infected ulcers, abscesses, scurvy, diabetic ketosis, gout, schizophrenia, phenylketonuria, defective metabolism of amino acids, hyperaminoaciduria, and the inability to metabolize butyric and hexanoic acids have all been recognized to lend a noxious or otherwise distinctive odor to sweat and other body secretions (Brown, 1995;Liddell, 1976; Thaler \& Hanson, 2005). While the malodor associated with some of these diseases is likely due to differences in the metabolism that lead to excretion of odd substances in the sweat and urine (e.g. phenylketonuria, defective metabolism of amino acids, diabetic ketosis, hyperaminoaciduria and the inability to metabolize butyric and hexanoic acids), no reason is given for the odor of the other diseases.

The ability to determine an individual's health status, particularly an individual one is considering as a potential mate, could be beneficial for two reasons. First, by determining that a conspecific is ill before coming into close contact with them for mating purposes, an individual can reduce their likelihood of contracting a contagious disease. This is the contagion indicator hypothesis suggested by Able (1996). Specifically, Able predicts that females should inspect male traits whose expression could indicate the presence and/or intensity of "associatively transmittable" parasites. By 
choosing to avoid males who are contagious, she reduces her risk of acquiring parasites and, where paternal care exists, she reduces the risk of her offspring becoming infected. Second, females may secure good genes for her offspring if she chooses to mate only with males who demonstrate genetic disease resistance (Hamilton \& Zuk, 1982). Females may determine which males have good genes by again inspecting traits whose expression depends on health and vitality.

Distinguishing between these two hypotheses can be difficult since both predict that women will inspect male traits which respond negatively to infection. However, if the preference women show for men with healthy traits, in this case, healthy odor, varies with the menstrual cycle, I may be able to determine the underlying evolutionary strategy behind her choice. Women who prefer the scent of healthy men at mid-cycle, when they would be most likely to conceive, are in all probability selecting for good genes. By paying special attention to cues of health during the fertile portion of her cycle, a woman is more likely to mate with a male who possesses genes for disease resistance which would be passed on to their offspring.

On the other hand, if women prefer the scent of healthy men most strongly in the late luteal phase of their cycle, when they are unlikely to conceive, but increased progesterone levels are causing immunosuppression, then they are most likely attempting to minimize their contact with contagious individuals during a vulnerable time. Choosing a healthy male to mate with during this later stage of her cycle will likely do nothing to secure good genes for a woman's offspring since she will not be conceiving any. But by maintaining her own health, a woman can maintain her reproductive value, her ability to have children in the future. Thus, if she is vulnerable to infection due to the 
immunsosuppressing effects of progesterone, she should be very sensitive to cues of illness in others so that she may avoid them.

While several mechanisms have been proposed to account for changes in body odor during times of illness, the activity of commensal microflora seems the most parsimonious explanation. This is because axillary secretions are entirely odorless until acted on by the commensal bacteria of the skin (Shelley et al., 1953). While the volatile acids and endocrine metabolites secreted in sweat most likely play a role in odor production (Penn \& Potts, 1998b), that role can only be to act as a substrate for bacterial activity as these components do not create an odor until liberated by bacterial enzymes (Froebe et al., 1990;Natsch et al., 2003;Zeng et al., 1992). No significant differences in the amount or composition of lipids in secretions have been found between people with different body odors but different microbial groups have been shown to create different odors (Leyden et al., 1981).

Axillary microflora are composed of Coryneforms, Micrococci, Propionibacteria and occasional gram negative rods (Leyden et al., 1981). Propionibacteria most likely do not contribute to body odor as they reside deep in the recesses of the sebaceous follicles. If they were involved in body odor, the apocrine sweat should be odorous by the time it reaches the surface and it is not (Leyden et al., 1981). Coryneforms give a typical musky body odor while Micrococci give a sweaty acid odor (Leyden et al., 1981). Gram negative rods contribute a wholly different odor which seems to defy description (Leyden et al., 1981). However what is important is not whether individuals can describe the odor they smell, but rather how they react to it. As long as individuals who respond negatively to the odor of illness increase their reproductive success by doing so, their genes will be 
favored by selection. It is not necessary that they be conscious of the decision they are making and how it benefits them. It is merely necessary that the decision they make does benefit them and their offspring.

The first step in determining how a woman benefits from discriminating between the odor of healthy and ill men is to determine if, indeed, women are discriminating between these odors. In this study I examined the role that health status plays in altering both the axillary microflora and the body odor of men. I asked women to rate the odors of these men in order to determine, first, if any difference was detectable and, second, if scent preferences could be attributed to selection for good genes or a desire to avoid contact with contagious individuals. If women are selecting for good genes, I predict that there will be a significant interaction between the health status of the males and the menstrual cycle phase of the women rating the males' odor. Specifically, women in the fertile phase of their cycle should rate the healthy males' odor as significantly more attractive than the ill males' odor. However, if women are attempting to avoid contagion, then women in the immunosuppressed phase of their cycles should rate the healthy males' odor as significantly more attractive than the ill males' odor.

\section{Methods}

\section{Male subjects}

Thirty-four healthy men, aged 18-47, and eighteen ill men, aged 19-39, volunteered to be odor donors. Reported illnesses are listed in Table 2. Subjects were recruited via word of mouth, either personal communication with me or with friends and colleagues familiar with my study, and flyers posted around the campus of the University 
Table 3. Illnesses reported by male subjects. Two men did not complete a health questionnaire.

\begin{tabular}{|c|c|}
\hline Illness & $\begin{array}{c}\text { \# Subjects } \\
\text { Reporting }\end{array}$ \\
\hline cold & 10 \\
\hline flu & 2 \\
\hline bronchitis & 2 \\
\hline mononucleosis & 1 \\
\hline crohn's disease & 1 \\
\hline unreported & 2 \\
\hline
\end{tabular}

of Louisville (see Appendices 2 and 3). Additionally, flyers and brochures were placed in the campus health clinic, and nurses were asked to bring the study to the attention of any men who came to the clinic seeking treatment for an illness. Due to privacy concerns, I was not able to recruit men directly at the health clinic. Flyers were also distributed to health clinics throughout the city of Louisville.

Following the protocol of Thornhill et al.(2003), odor donors were provided with a t-shirt to wear for two nights, as well as unscented soap and unscented detergent. Men were asked to adhere to the following restrictions: 1) Use only the unscented soap provided; 2) if scented products (i.e. cologne, deodorant) are used during the day, wash them off before going to bed; 3) wash bedclothes in the unscented detergent provided; 4) do not use dryer sheets; 5) do not eat garlic, onion, green chile, pepperoni, pungent spices, herbs, strong cheeses, cabbage, celery, asparagus, yogurt, or lamb or any foods containing any of these items; 6) do not consume alcohol or use recreational drugs; 7) do not smoke tobacco; 8) do not engage in sex with another person; and 9) do not sleep with another person. Upon returning the shirts men were asked to fill out a questionnaire asking them which, if any, of the restrictions they had failed to follow. They were 
advised that their answers would not affect their compensation and honesty was very important. After the second night, the shirts were returned in sealed plastic bags, where they remained until rated by our female volunteers. Two healthy men and two ill men failed to return their shirts. Lag time between shirt collection and odor rating ranged from as little as one day to as long as seven months for one shirt. Most shirts were rated within 2-3 days of being collected. Male volunteers received either $\$ 20$ or course credit as compensation for their time and inconvenience.

\section{Female subjects}

Fifty-seven women aged 18-54 volunteered to rate the odor of the t-shirts. Women were recruited via word of mouth and flyers posted around the campus of the University of Louisville (see appendix 2). Each woman rated all the shirts on three subjective scales: pleasantness, sexiness, and intensity. A sample rating sheet can be found in appendix 4. The use of three separate odor measures allowed us to assess whether odors were being rated as unattractive because they had some noxious component or merely because they were strong. Additionally women were asked to indicate if they smelled any artificial odors on the t-shirt (i.e. cologne, deodorant, soap, cigarette smoke, etc). Whenever a woman indicated this was the case, her rating of that shirt was removed from the analysis. Due to artificial odors, 304 observations had to be eliminated from the analysis. The shirts were presented to women in boxes of 9-10 shirts in order to facilitate having multiple raters present at one time. The shirts were assigned to boxes randomly. Each box also contained a control shirt which had been washed in 
unscented detergent as had the others, but had not been worn. Rating sessions typically lasted less than one hour.

Women also provided information on their menstrual cycle and contraceptive use as these may affect scent preferences (Wedekind et al., 1995). Unfortunately, most subjects were unable to provide me with information regarding the length of their menstrual cycle so I had to assume a 28-day cycle for these women. Using this information and women's reported last date of menstruation, I was able to assign an approximate menstrual phase to each woman. For example, a woman with a 28-day cycle was considered fertile if she was on day 9-15 of her cycle (Ferreira-Poblete, 1997) and was considered most likely to be experiencing high progesterone if she was on day 18-24 of her cycle (Alters \& Alters, 2006). A full description of menstrual cycle phase assignments is given in Table 4 .

Table 4. Assigned menstrual cycle phase of all female subjects based on their reported first day of last menstrual period. The days of cycle shown are based on a 28-day menstrual cycle.

\begin{tabular}{|c|c|c|}
\hline $\begin{array}{c}\text { Menstrual Cycle } \\
\text { Phase }\end{array}$ & $\begin{array}{c}\text { Days of } \\
\text { cycle }\end{array}$ & $\begin{array}{c}\text { Number Female } \\
\text { Subjects }\end{array}$ \\
\hline Follicular & $1-8$ & 5 \\
\hline Fertile & $9-15$ & 8 \\
\hline Early Luteal & $16-17$ & 2 \\
\hline Mid-Luteal & $18-24$ & 4 \\
\hline Late Luteal & $25-28$ & 8 \\
\hline Contraception & $\mathrm{n} / \mathrm{a}$ & 28 \\
\hline Post-menopausal & $\mathrm{n} / \mathrm{a}$ & 1 \\
\hline Unreported & $\mathrm{n} / \mathrm{a}$ & 1 \\
\hline
\end{tabular}


Because I was primarily interested in odor preferences as they relate to mating preferences, I only included women of reproductive age and heterosexual orientation in the analysis. I asked women to rate their sexual orientation on a scale from $0-5,0$ being exclusively heterosexual, 5 being exclusively homosexual. Three women were excluded from the analysis because they reported being exclusively or nearly exclusively homosexual. One woman was excluded from the analysis because she reported being post-menopausal. Female volunteers received either $\$ 10$ or course credit for their time and inconvenience. All subjects were identified by a computer-generated random number and nothing else. I maintained no personal identifiers for any of my subjects.

\section{Axillary microflora}

A sample of the community of commensal microbes was taken from one axilla of each male subject by swabbing the area with a cotton swab that had been soaked in sterile saline. I then inoculated $10 \mathrm{ml}$ of sterile nutrient broth with the swab. Cultures were incubated for 24 hours at $37^{\circ} \mathrm{C}$ and then serially diluted and counted using a standard plate count technique. Subjects were asked to refrain from wearing deodorant the day of the swabbing. Four ill men failed to do this and as a result, their bacterial samples could not be included in the analysis. Because odortypes were attributed to larger groups of bacteria (i.e. Corynebacteria, Brevibacteria, Staphylococcus, Micrococcus, and gram negative, see above), as opposed to different odors being attributed on a species by species basis, I limited my identification to these five larger groups.

The organisms present were identified to the genus level (for gram positive species) following Bergey's Manual of Determinative Microbiology. A gram stain was 
used to identify bacteria as either gram positive or gram negative. In addition, visualization of the stained bacteria allowed me to determine whether gram positive organisms were rod-shaped (Corynebacteria or Brevibacteria) or cocci (Micrococcus or Staphylococcus). I was able to distinguish between the gram positive rods using a gelatinase test. Corynebacteria are gelatinase negative while Brevibacteria are gelatinase positive. I distinguished between the gram positive cocci by challenging them with the antibiotic bacitracin. Staphylococcus are resistant to bacitracin but Micrococcus are susceptible.

\section{Statistical analyses}

Using an ANOVA, I analyzed the effect of men's health as well as women's menstrual cycle phase on women's perception of the pleasantness, sexiness, and intensity of the men's body odor. Where significant differences were found, I used a Tukey's HSD test with an experiment-wise error rate of 0.05 to determine exactly which means were significantly different. Additionally, I performed a Pearson pair-wise correlation test on the three ratings, pleasantness, sexiness, and intensity to determine if and how these measures were related. I also examined the data using ANOVA for evidence of age effects or effects of when, compared to other women, a woman was rating a shirt. For example, did women who rated shirts on the first day perceive the odors differently than women who rated shirts on the last day.

I compared the overall density of axillary microflora between healthy and ill men using a one-factor ANOVA. Because the data were non-normally distributed I used a square-root transformation to meet the assumptions of the model. Additionally, I 
compared the likelihood of the presence of Corynebacteria or Micrococcus in the axillary microflora between healthy and ill men using a logistic regression. An insufficient number of subjects possessed any Brevibacterium, Staphylococcus, or gram negative species to run an analysis on these taxa (Table 5).

Table 5. Number of male subjects with each bacterial group among their axillary microflora. Bacterial samples from a total of 34 healthy men and 14 ill men were collected.

\begin{tabular}{|c|c|c|}
\hline Taxon & Healthy Men & Ill Men \\
\hline Corynebacteria & 21 & 9 \\
\hline Brevibacteria & 2 & 2 \\
\hline Micrococcus & 14 & 10 \\
\hline Staphylococcus & 2 & 0 \\
\hline Gram Negative & 0 & 0 \\
\hline
\end{tabular}

\section{Results}

\section{Attractiveness of odors}

All three measures of attractiveness were significantly correlated with each other, however the strength of the relationships was insufficient $(r<0.75)$ to warrant the creation of a composite measure. Pleasantness and sexiness showed the strongest correlation with $r=0.68(p<0.0001)$. Intensity was weakly negatively correlated with pleasantness, $r=-0.26(p<0.0001)$, and sexiness, $r=-0.10(p<0.0001)$. I therefore ran three separate analyses with each of the measures as a unique dependent variable.

Male age did not significantly affect how pleasant (ANOVA, $F=0.00, p=0.96$ ), how sexy (ANOVA, $F=0.47, p=0.49)$, or how intense (ANOVA, $F=0.08, p=0.78)$ 
women found the scent of men's shirts. Similarly, female age did not significantly affect how pleasant (ANOVA, $\mathrm{F}=1.07, \mathrm{p}=0.14)$, how sexy (ANOVA, $\mathrm{F}=2.15, \mathrm{p}=0.12)$, or how intense (ANOVA, $F=0.55, \mathrm{p}=0.46$ ) women found the scent of men's shirts. Which day, relative to other women, a woman rated a shirt's odor also did not significantly affect how pleasant (ANOVA $F=2.14, p=0.14)$, how sexy (ANOVA, $F=2.21 p=$ 0.12 ) or how intense (ANOVA, $\mathrm{F}=0.14, \mathrm{p}=0.71$ ) she found the odor.

Male health did not significantly affect how pleasant women found the smell of the shirts (Fig. 3), however women did prefer the scent of the control shirts to the scent of the shirts worn by men (ANOVA, $F=11.08, \mathrm{p}<0.0001$ ). Women's menstrual cycle phase did predict how attractive they found the smell of each shirt (ANOVA, F $=11.31$, $\mathrm{p}<0.0001)$. In particular, women in the follicular phase and women in the early luteal phase of their cycles found shirts to smell more pleasantly than women who were fertile, women who were in the mid- or late luteal phase of their cycles, or women who were taking hormonal contraceptives (Fig. 4). Overall, women rated the scent of shirts as 2.3 $(\mathrm{SE}=0.03)$ on the $0-5$ pleasantness scale. Women in the follicular phase of their cycles, however, rated the scent of shirts as 3.2 on average $(\mathrm{SE}=0.08)$ and women in the early luteal phase of their cycles rated the scent of shirts as 2.8 on average $(\mathrm{SE}=0.15)$.

Male health also did not significantly affect how sexy women found the smell of the shirts (Fig. 5), however women did again discriminate between the control shirts and the shirts worn by men (ANOVA, $\mathrm{F}=3.36, \mathrm{p}=0.03$ ). The differences were not large enough to be discriminated by Tukey's HSD but the trend was for control shirts to be perceived as smelling sexier than shirts worn by men. Again, women in the follicular phase and women in the early luteal phase of their cycles found the scent of shirts to be 
sexier than women who were in any other phase of their cycle and women using hormonal contraceptives (ANOVA, $F=35.95$, $p<0.0001$; Fig. 6). Overall, women rated the scent of shirts as $1.5(\mathrm{SE}=0.04)$ on the $0-5$ sexiness scale. Women in the follicular phase of their cycles, however, rated the scent of shirts as $2.9(\mathrm{SE}=0.11)$ and women in the early luteal phase of their cycles rated the scent of shirts as $2.6(\mathrm{SE}=0.18)$.

Finally, male health did not significantly affect how strong women found the smell of the shirts (Fig. 7), but women did find the shirts worn by men to smell stronger than the control shirts (ANOVA, $F=21.23, \mathrm{p}<0.0001)$. Menstrual phase also significantly affected how strong the women perceived the scent of the shirts to be (ANOVA, $\mathrm{F}=26.15, \mathrm{p}<0.0001$ ). Women who were most likely to be fertile as well as those in the mid- and late luteal phases of their cycles rated the shirts as smelling more strongly than women in the follicular or early luteal phases of their cycles or women using hormonal contraceptive (Fig. 8). Overall women rated the scent of shirts as 2.2 (SE $=0.03$ ) on the $0-5$ intensity scale. Women who were most likely to be fertile, however, rated the scent of shirts as $2.9(\mathrm{SE}=0.09)$. Women in the mid-luteal phase of their cycles rated the scent of shirts as $2.8(\mathrm{SE}=0.13)$ and women in the late luteal phase of their cycles rated the scent of shirts as $2.8(\mathrm{SE}=0.09)$.

\section{Axillary microflora}

The density of organisms in the commensal microflora of the axillae of healthy men and ill men was not significantly different (ANOVA, $F=0.00, p=0.95)$. Nor were ill men more or less likely to possess Corynebacteria in the community of commensal microflora on the skin of their axillae (Logistic regression, $\chi^{2}=0.03, \mathrm{p}=0.87$ ). 
However, ill men were more likely to possess Micrococcus in the community of commensal microflora on the skin of their axillae (Logistic regression, $\chi^{2}=3.44, p=$ 0.06, Fig. 6).

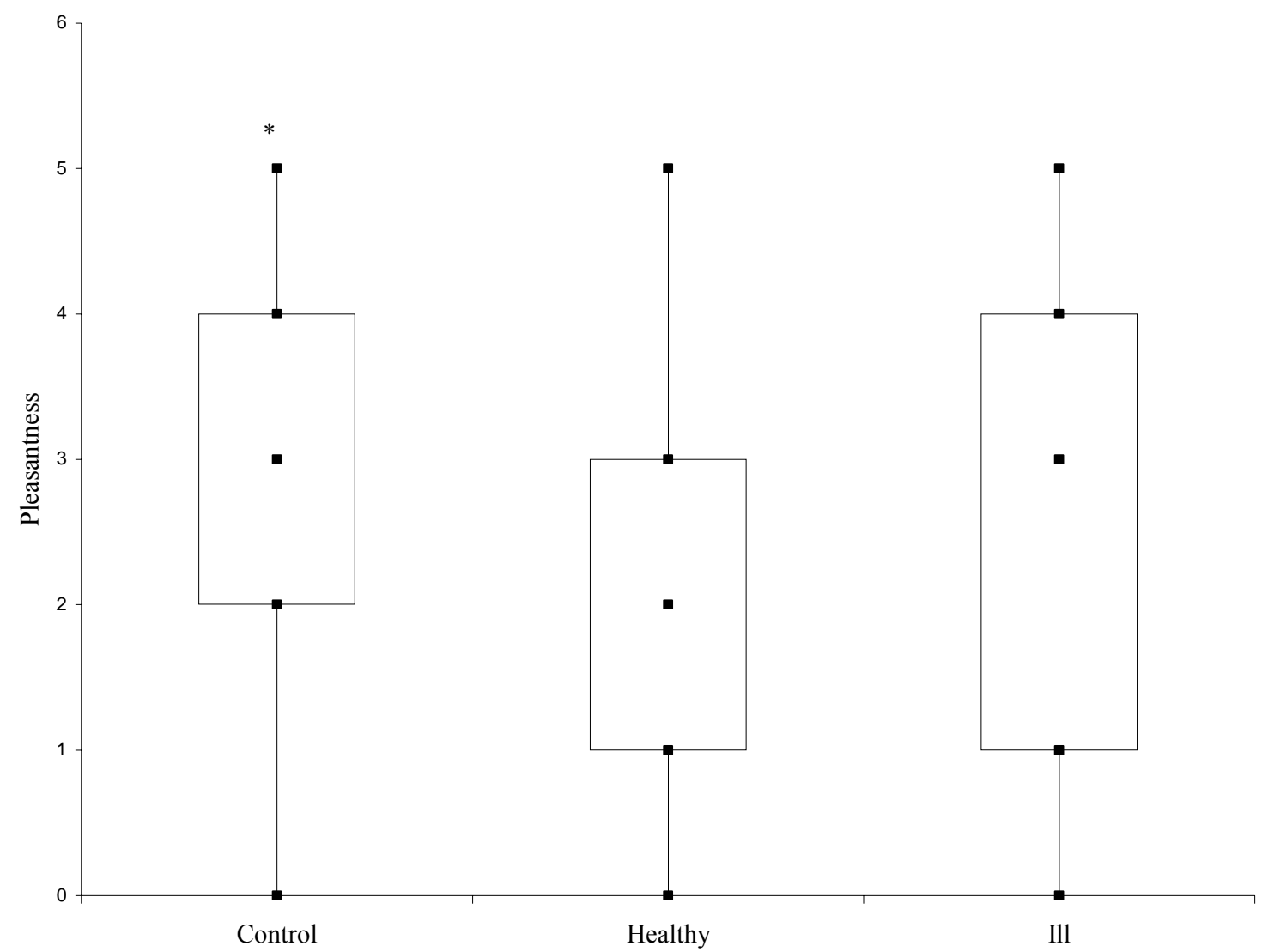

Figure 3. Women found the odor of unworn shirts to be more pleasant than the odor of either healthy or ill shirts (ANOVA, $\mathrm{F}=11.08, \mathrm{p}<0.0001$ ). There was no significant difference between the odor of healthy and ill shirts. Significant differences are indicated by an asterisk. 


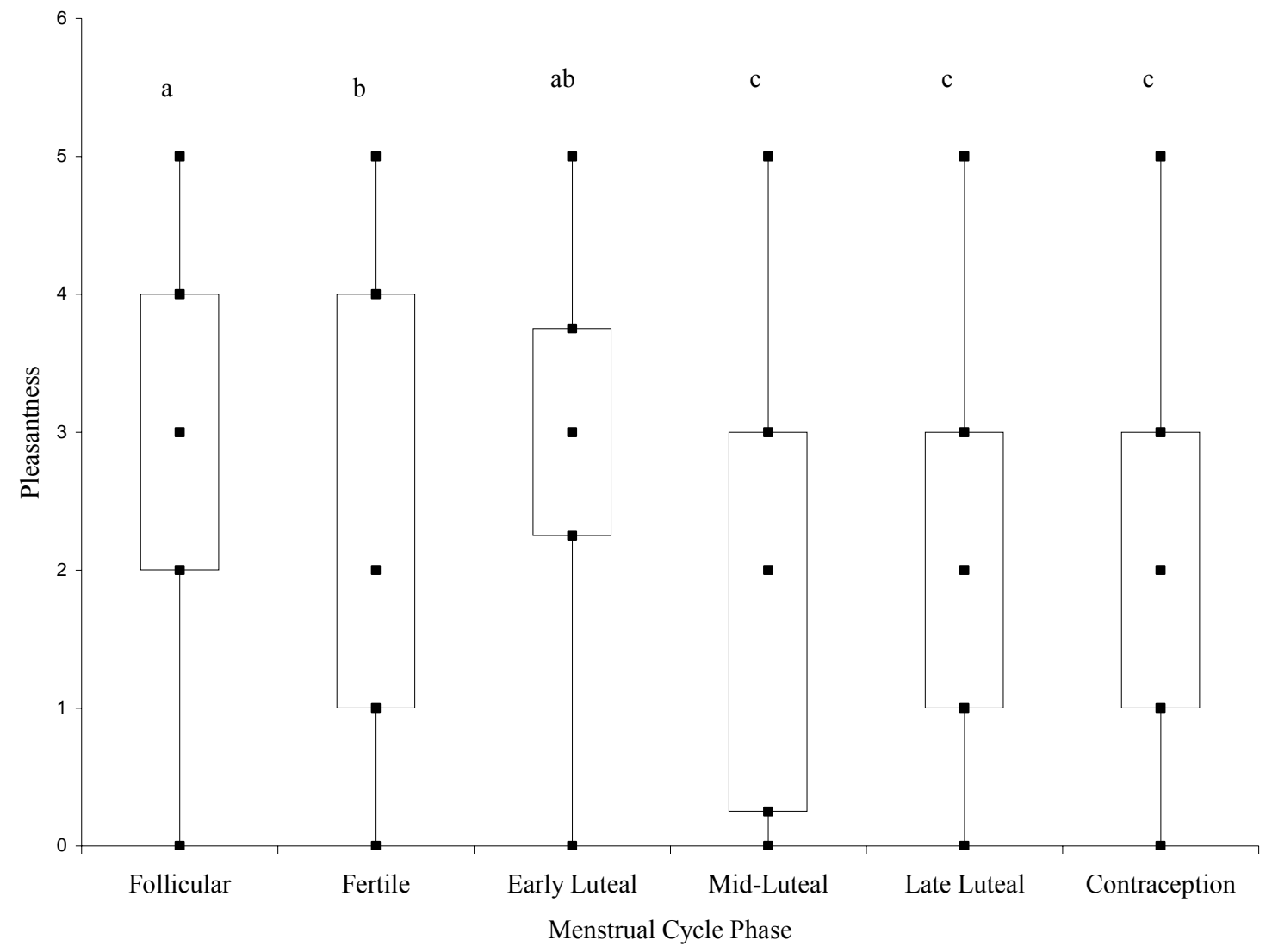

Figure 4. Women in the follicular and early luteal phases of their menstrual cycles found the scent of shirts more pleasant than women in any other phase of their cycle or women using hormonal contraceptive (ANOVA, $F=11.31, \mathrm{p}<0.0001$ ). Boxes with different letters are significantly different at the 0.05 level. 


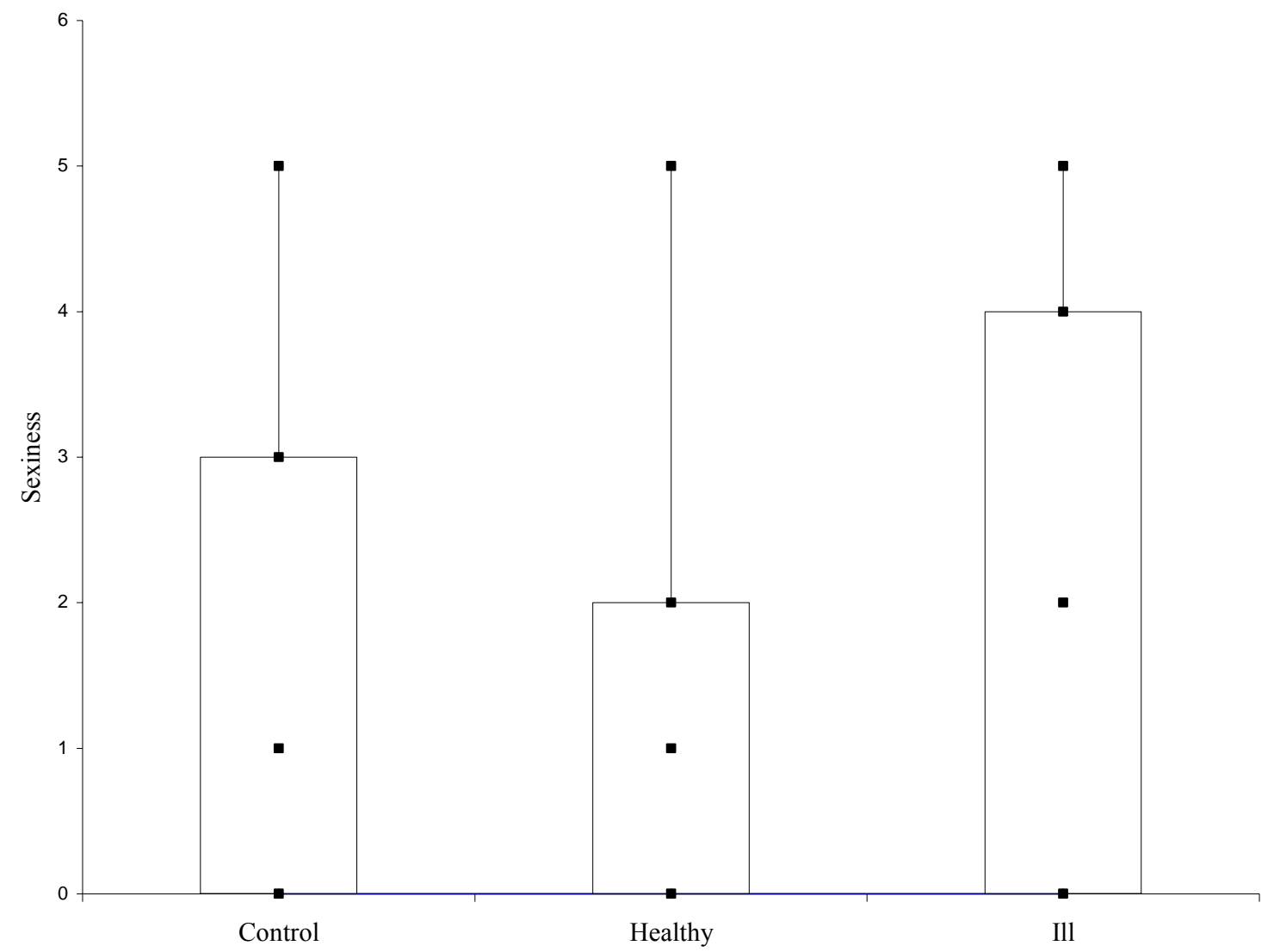

Figure 5. Women discriminated between the odor of the control shirts and the shirts worn by men (ANOVA, $F=3.36, p=0.03$ ). The differences were not large enough to be discriminated by Tukey's HSD but the trend was for control shirts to be perceived as smelling sexier than shirts worn by men. 


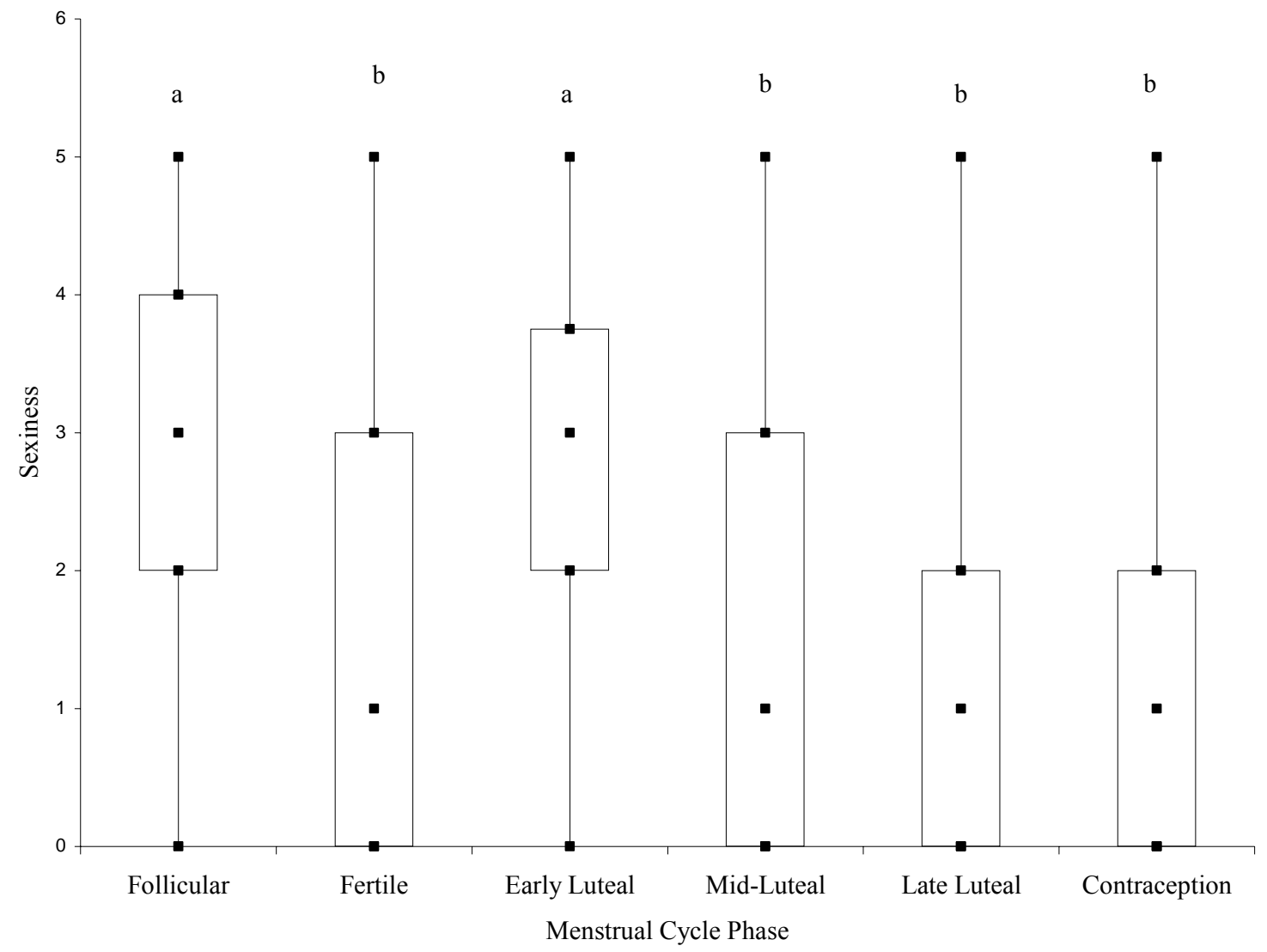

Figure 6. Women in the follicular and early luteal phases of their menstrual cycles found the scent of shirts to be sexier than women in any other phase of their cycle or women using hormonal contraceptive (ANOVA, $F=35.95, \mathrm{p}<0.0001$ ). Boxes with different letters are significant at the 0.05 level. 


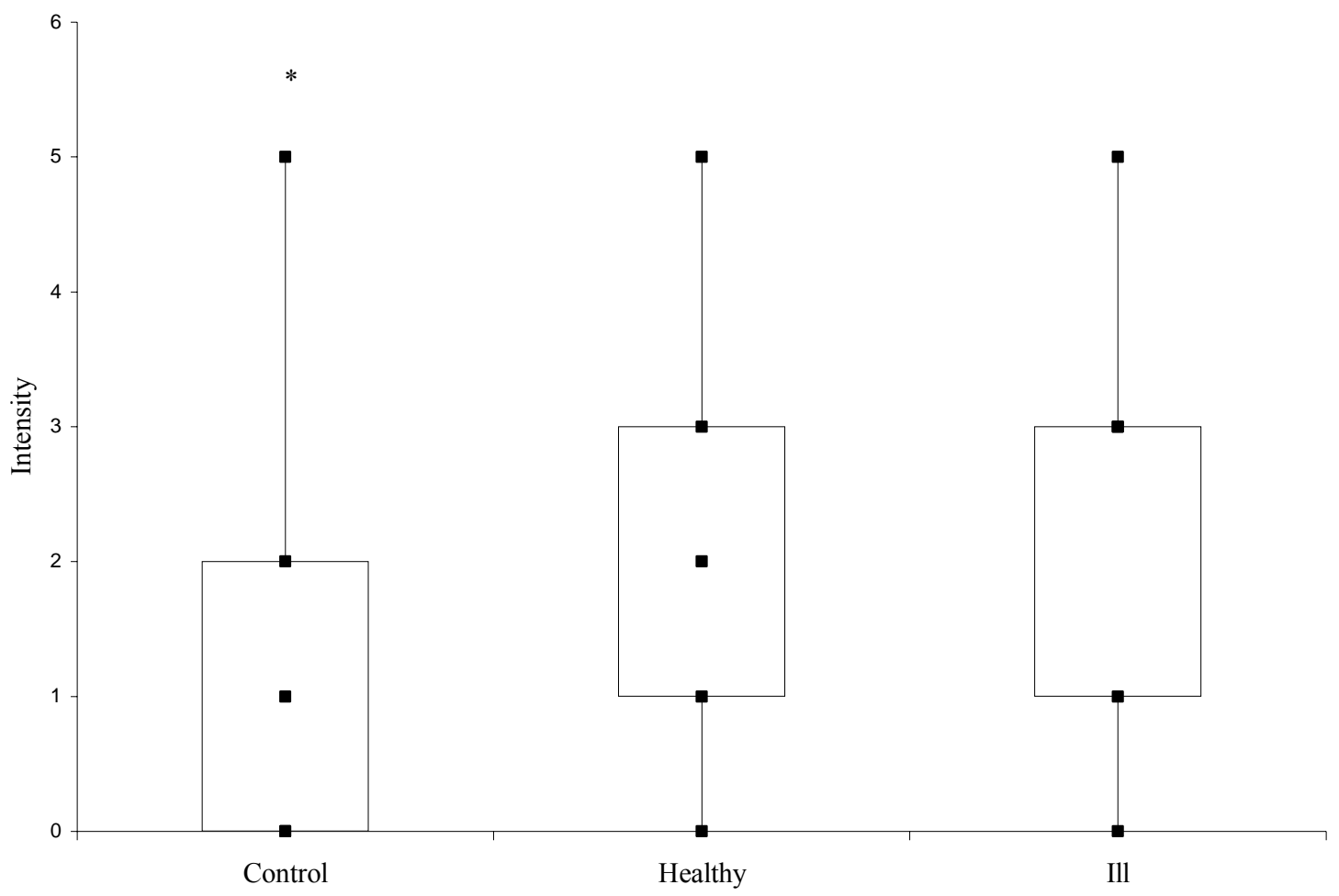

Figure 7. Women found the odor of unworn shirts to be less intense than the odor of either healthy or ill shirts (ANOVA, $\mathrm{F}=21.23, \mathrm{p}<0.0001$ ). There was no significant difference between the odor of healthy and ill shirts. Significant differences are indicated by an asterisk 


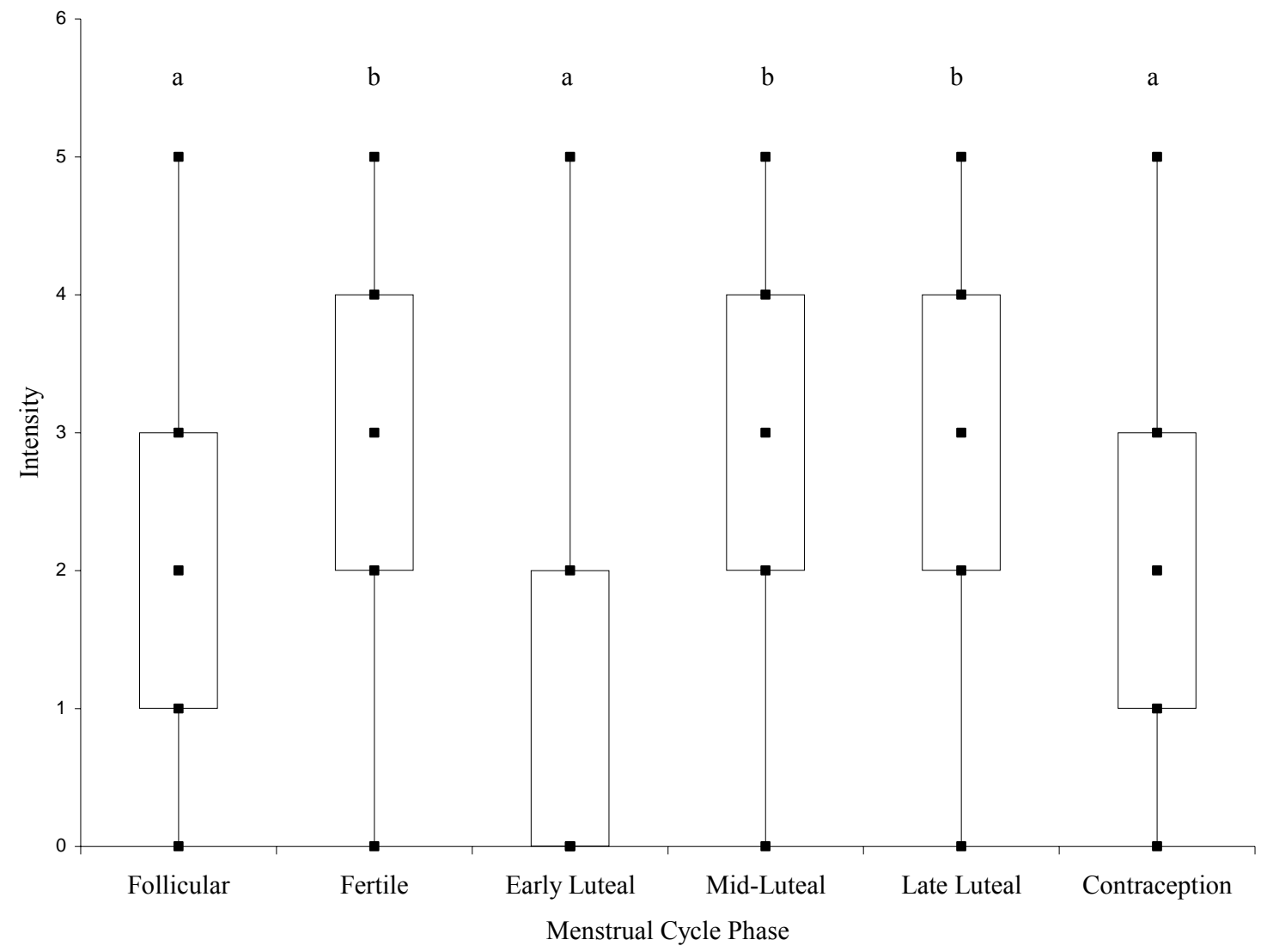

Figure 8. Women in the fertile, mid-luteal, and late luteal phases of their menstrual cycles found the scent of shirts to be stronger than women in any other phase of their cycle or women using hormonal contraceptive (ANOVA, $F=26.15, p<0.0001$ ). Boxes with different letters are significant at the 0.05 level. 


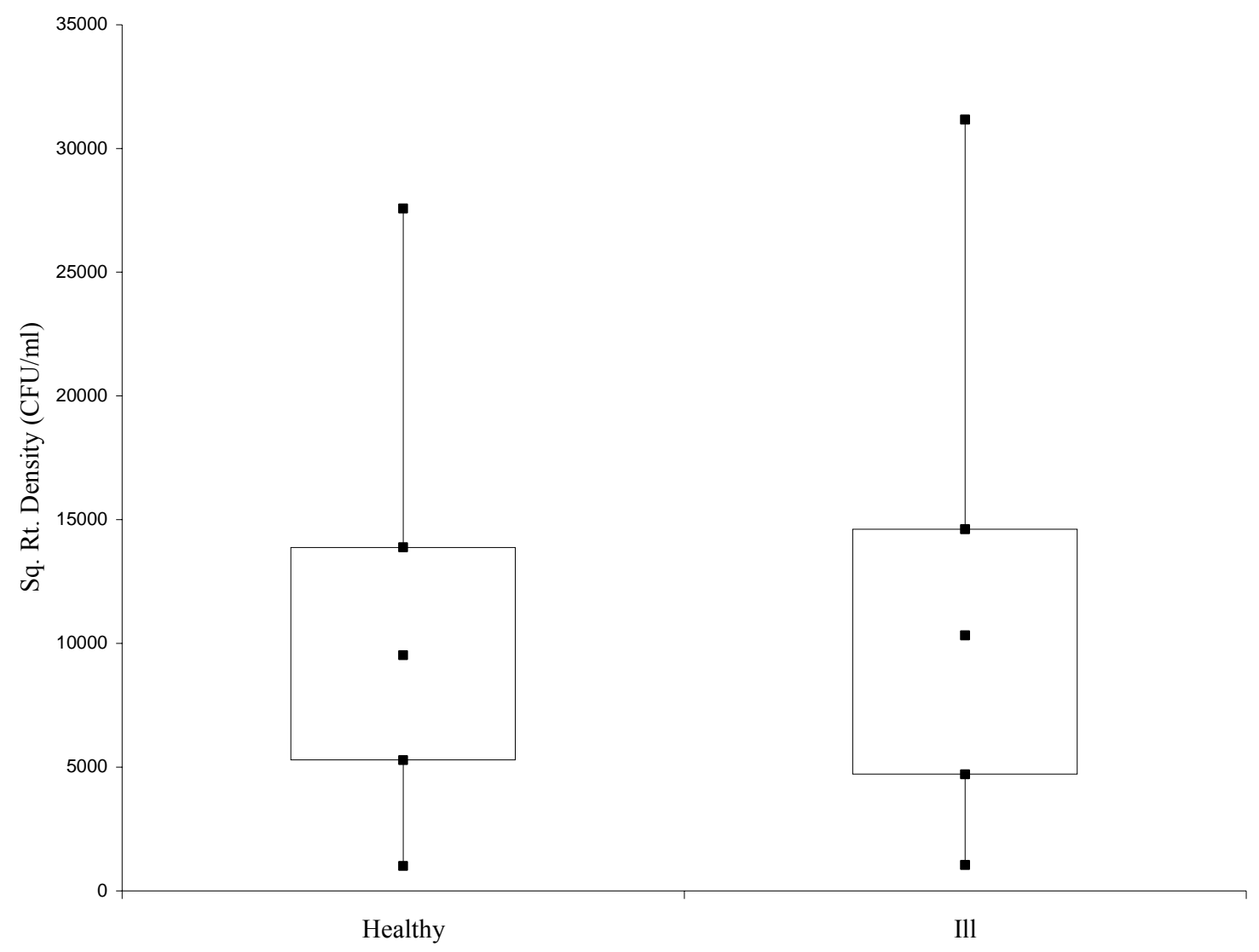

Figure 9. There was no significant difference in the density of axillary microflora between healthy and ill men (ANOVA, $F=0.00, p=0.95)$. 


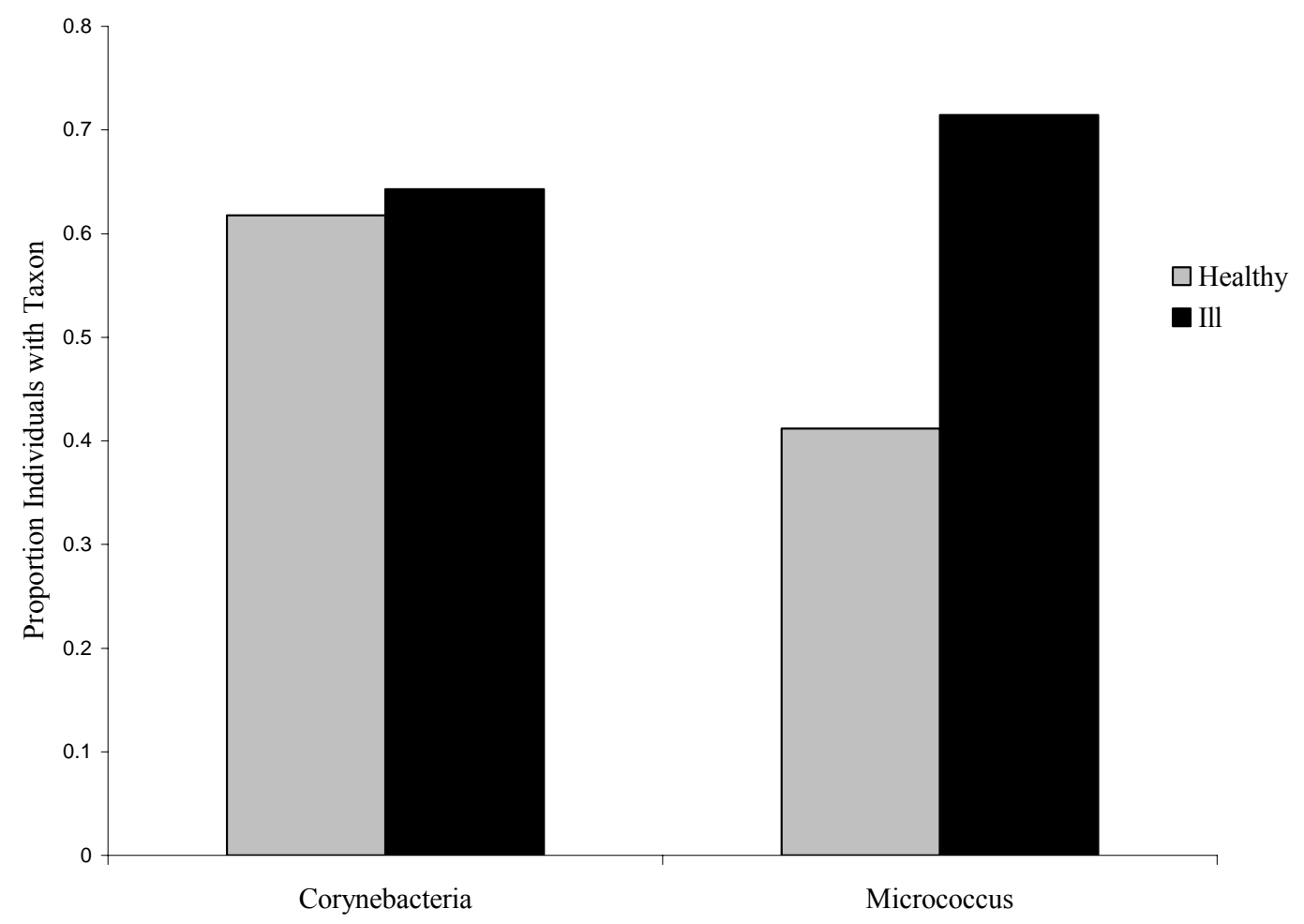

Figure 10. Healthy men and ill men are equally likely to possess Corynebacteria in the community of commensal microflora on the skin of their axillae (Logistic regression, $\chi^{2}=$ $0.03, \mathrm{p}=0.87)$. Healthy men are only 0.28 times as likely as ill men to possess Micrococcus in the community of commensal microflora on the skin of their axillae (Logistic regression, $\chi^{2}=3.44, \mathrm{p}=0.06$ ).

\section{Discussion}

The purpose of this study was to determine whether a male's illness alters how attractive women find that male's odor and to determine whether illness alters the axillary microflora of men. The results of this study do not support the hypothesis that illness 
alters how attractive women find a man's odor but do support the hypothesis that the community of axillary microflora is altered in ill males.

It does not appear that women are able to distinguish between the odors of healthy and ill males, let alone demonstrate a preference for one or the other. The majority of the ill men in this study were experiencing only a cold which may not be a severe enough condition to warrant an avoidance response from women. While illness has been shown to have a strong effect on the attractiveness of body odor in mice (Kavaliers \& Colwell, 1995a, b;Kavaliers et al., 1997;Penn et al., 1998;Yamazaki et al., 2002;Zala et al., 2004), all these studies involved infecting mice with pathogens which could be considered quite a bit more threatening to fitness than the common cold is to humans (e.g. mouse mammary tumor virus, protozoan parasites, bacterial pathogens). Perhaps there is simply not enough selective pressure on women to distinguish between the odors of healthy males and the odors of males currently infected with a minor respiratory virus that has little to no effect on reproductive fitness and that most, if not all, men will contract at some point in their lives.

It is interesting that women in the follicular and early luteal phases of their cycles found the odors in general to be more pleasant and sexier than women in other phases of their cycles. In previous studies (S. W. Gangestad, 1998; Thornhill et al., 2003; Wedekind \& Füri, 1997; Wedekind et al., 1995) women found the scent of men's shirts to be most attractive during the fertile phase of their cycles.

Previous work has also found that women show an increase in olfactory sensitivity at mid-cycle, during the mid-luteal phase, around the time of menses, or not at all (Doty et al., 1982;Herberhold et al., 1982). My finding that women at mid-cycle, the 
fertile phase of the cycle, as well as women in the mid- and late luteal phases of their cycles demonstrated a significant increase in ratings of scent intensity relative to other women in the study bolsters previous work demonstrating increases in olfactory sensitivity at these times of the cycle. The reason for this increase is still unclear since it has been shown that the changes in olfactory sensitivity are not related to cyclical changes in hormone levels (Doty et al., 1982).

In addition, perhaps the finding that women in the follicular and early luteal phases of their cycles found the odor of shirts to be less intense than other women explains why women in the follicular and early luteal phases of their cycles found the odor of shirts to be more attractive than did other women. If this were the case, however, I would have expected to find that women using hormonal contraception, who also demonstrated a decreased olfactory sensitivity, would have also found the odors of shirts relatively attractive, which they did not.

Even though I did not find evidence that men's body odor is changed during illness, at least not sufficiently enough to affect women's perception of the odor, it is clear that the axillary microflora are altered. Ill men are much more likely to possess a Micrococcus species than healthy men are. It is odd that women did not detect a difference in the odor since it has been shown that Micrococcus created an entirely different odor than other taxa (Leyden et al., 1981). Two possible explanations for this are that: 1) women did detect a different odor but found it no more or less pleasant or sexy than the odor of healthy men, and 2) since ill men were just as likely as healthy men to possess Corynebacteria species, the odor of this group of bacteria masked the odor of the Micrococcus. Future work should perhaps aim to determine women's sensitivity to 
the odors created by these two bacterial groups. Is the odor of one group stronger than the other? Do women find the odor of one group more or less attractive than the other?

Even though women did not detect a difference in the odors in this study, the fact that the commensal microflora of ill men is different from that of healthy men suggests that the possibility of olfactory discrimination still exists. Perhaps priming women for a mate selection activity through the use of short narratives would increase the ability to detect an effect. However such priming has not been necessary to detect an effect in previous odor preference studies (S. W. Gangestad, 1998;Thornhill \& Gangestad, 1999; Thornhill et al., 2003; Wedekind \& Füri, 1997; Wedekind et al., 1995) Alternatively, it may be that though discrimination of body odor is possible, it does not take place in the context of sexual selection. Future research should explore these possibilities. 


\section{CHAPTER 4}

\section{SIMILARITY OF COMMENSAL MICROFLORA AFFECTS THE SEXINESS OF MEN'S ODOR}

\section{Introduction}

The genes of the major histocompatibility complex (MHC) are the most

polymorphic coding loci known in vertebrates. One explanation that has been suggested for these polymorphisms is disassortative mating preferences (Apanius et al., 1997;Penn \& Potts, 1999). Penn (2002) suggests two advantages to disassortative mating. First, it may increase the resistance of offspring to infectious diseases. This could occur either because of a heterozygote advantage or because producing offspring with variable $\mathrm{MHC}$ types creates a moving target for rapidly evolving parasites. Second, disassortative mating may be operating in order to avoid inbreeding. Evidence for disassortative mating has been found in mice, salmon, and humans (Landry et al., 2001;Manning et al., 1992;Ober et al., 1997).

Due to mate selection, wild populations of female mice produced more $\mathrm{MHC}$ heterozygous offspring than expected by chance (Manning et al., 1992). Atlantic salmon appear to choose their mates in order to increase the heterozygosity of their offspring at the peptide-binding region of the MHC (Landry et al., 2001). And among the Hutterites, a North American reproductively isolated group of European ancestry, it was found that the likelihood of married couples sharing MHC alleles was significantly lower 
than chance (Ober et al., 1997). Unlike other studies which have not taken population structure into account or did not examine extramarital copulations (Hedrick \& Black, 1997; Ihara et al., 2000) this study did find a disassortative pattern with respect to MHCtype.

It appears that the distinction between MHC-type of individuals is mediated by chemical signals. The ability of mice and rats to distinguish between the odors of individuals who differ only at one or more loci of the MHC has been known for two decades (Brown et al., 1989;Brown et al., 1987;Manning et al., 1992). In addition rats (Ferstl et al., 1992) and dogs (Hepper, 1988) have also been shown to discriminate between the odors of MHC dissimilar humans. Humans have been able to distinguish between odors of mice differing only in MHC-type (Gilbert et al., 1986) and women specifically have been found to prefer the scent of MHC-dissimilar men (Wedekind et al., 1995). These preferences are usually correlated with menstrual cycle phase with women showing the strongest preference for dissimilarity during the late follicular phase, the time when probability of coneception is highest (Thornhill et al., 2003; Wedekind \& Füri, 1997; Wedekind et al., 1995).

How MHC genotypes contribute to specific odortypes, however, remains a mystery. One hypothesis suggests that since it is the microflora which ultimately produce odor (Froebe et al., 1990;Natsch et al., 2003; Shelley et al., 1953;Zeng et al., 1992), perhaps the MHC-type influences odor by controlling the composition of commensal microbes. Experimental work with rats has shown support for this hypothesis. Rats that have been raised in a germ-free environment were no longer distinguishable to other rats. Once these rats were returned to normal housing, and the commensal microflora therein, 
they were discriminable (Singh et al., 1990). In addition, treating rats with antibacterial agents altered the maternal odors as well as body odors of adult males (Brown \& Schellinck, 1992).

If it is true that MHC-type creates specific odortypes via control of commensal microbes, then we should expect to see scent preferences in humans that correlate with microflora similarity/dissimilarity in much the same pattern as has been shown for MHCdissimilarity. Specifically, women should prefer the scent of men who have a dissimilar community of commensal microbes from themselves and this preference should be strongest during the most fertile portion of the menstrual cycle.

\section{Methods}

\section{Male subjects}

Thirty men aged 18-47 volunteered to be odor donors. Subjects were recruited via word of mouth, either personal communication with me or with friends and colleagues familiar with my study, and flyers posted around the campus of the University of Louisville (see Appendix 2). Following the protocol of Thornhill et al.(2003), odor donors were provided with a t-shirt to wear for two nights, as well as unscented soap and unscented detergent. Men were asked to adhere to the following restrictions: 1) Use only the unscented soap provided; 2) if scented products (i.e. cologne, deodorant) are used during the day, wash them off before going to bed; 3) wash bedclothes in the unscented detergent provided; 4) do not use dryer sheets; 5) do not eat garlic, onion, green chile, pepperoni, pungent spices, herbs, strong cheeses, cabbage, celery, asparagus, yogurt, or lamb or any foods containing any of these items; 6) do not consume alcohol or use 
recreational drugs; 7) do not smoke tobacco; 8) do not engage in sex with another person; and 9) do not sleep with another person. Upon returning the shirts men were asked to fill out a questionnaire asking them which, if any, of the restrictions they had failed to follow. They were advised that their answers would not affect their compensation and honesty was very important. After the second night, the shirts were returned in sealed plastic bags, where they remained until rated by our female volunteers. Lag time between shirt collection and odor rating ranged from as little as one day to as long as five months. Most shirts were rated within 2-3 days of being collected. Male volunteers received either $\$ 20$ or course credit as compensation for their time and inconvenience.

\section{Female Subjects}

Fifty-seven women aged 18-54 volunteered to rate the odor of the t-shirts.

Women were recruited via word of mouth and flyers posted around the campus of the University of Louisville (see Appendix 2). Each woman rated the shirts on three subjective scales: pleasantness, sexiness, and intensity. A sample rating sheet can be found in Appendix 4. The use of three separate odor measures allowed us to assess whether odors were being rated as unattractive because they had some noxious component or merely because they were strong. Additionally women were asked to indicate if they smelled any artificial odors on the t-shirt (i.e. cologne, deodorant, soap, cigarette smoke, etc). Whenever a woman indicated this was the case, her rating of that shirt was removed from the analysis. Due to artificial odors, 184 observations had to be eliminated from the analysis. The shirts were presented to women in boxes of 9-10 shirts 
in order to facilitate having multiple raters present at one time. The shirts were assigned to boxes randomly. Rating sessions typically lasted less than one hour.

Women also provided information on their menstrual cycle and contraceptive use as these may affect scent preferences (Wedekind et al., 1995). Unfortunately, most subjects were unable to provide me with information regarding the length of their menstrual cycle so I had to assume a 28-day cycle for these women. Using this information and women's reported last date of menstruation, I was able to assign an approximate menstrual phase to each woman. For example, a woman with a 28-day cycle was considered fertile if she was on day 9-15 of her cycle. A full description of menstrual cycle phase assignments is given in Table 6 .

Table 4. Assigned menstrual cycle phase of all female subjects based on their reported first day of last menstrual period. The days of cycle shown are based on a 28-day menstrual cycle.

\begin{tabular}{|c|c|c|}
\hline $\begin{array}{c}\text { Menstrual Cycle } \\
\text { Phase }\end{array}$ & $\begin{array}{c}\text { Days of } \\
\text { cycle }\end{array}$ & $\begin{array}{c}\text { Number Female } \\
\text { Subjects }\end{array}$ \\
\hline Follicular & $1-8$ & 5 \\
\hline Fertile & $9-15$ & 8 \\
\hline Early Luteal & $16-17$ & 2 \\
\hline Mid-Luteal & $18-24$ & 4 \\
\hline Late Luteal & $25-28$ & 8 \\
\hline Contraception & $\mathrm{n} / \mathrm{a}$ & 28 \\
\hline Post-menopausal & $\mathrm{n} / \mathrm{a}$ & 1 \\
\hline Unreported & $\mathrm{n} / \mathrm{a}$ & 1 \\
\hline
\end{tabular}

Because I was primarily interested in odor preferences as they relate to mating preferences, I only included women of reproductive age and heterosexual orientation in 
the analysis. I asked women to rate their sexual orientation on a scale from $0-5,0$ being exclusively heterosexual, 5 being exclusively homosexual. Three women were excluded from the analysis because they reported being exclusively or nearly exclusively homosexual. One woman was excluded from the analysis because she reported being post-menopausal. Female volunteers received either $\$ 10$ or course credit for their time and inconvenience. All subjects were identified by a computer-generated random number and nothing else. I maintained no personal identifiers for any of my subjects.

\section{Axillary microflora}

A sample of the community of commensal microbes was taken from one axilla of each subject by swabbing the area with a cotton swab that had been soaked in sterile saline. Subjects were asked to refrain from wearing deodorant on the day the swabs would be taken. I then inoculated $10 \mathrm{ml}$ of sterile nutrient broth with the swab. Cultures were incubated for 24 hours at $37^{\circ} \mathrm{C}$ and then serially diluted and counted using a standard plate count technique. Because odortypes were attributed to larger groups of bacteria (i.e. Corynebacteria, Brevibacteria, Staphylococcus, Micrococcus, and gram negative, see above), as opposed to different odors being attributed on a species by species basis, I limited my identification to these five larger groups.

The organisms present were identified to the genus level (for gram positive species) following Bergey's Manual of Determinative Microbiology. A gram stain was used to identify bacteria as either gram positive or gram negative. In addition, visualization of the stained bacteria allowed me to determine whether gram positive organisms were rod-shaped (Corynebacteria or Brevibacteria) or cocci (Micrococcus or 
Staphylococcus). I was able to distinguish between the gram positive rods using a gelatinase test. Corynebacteria are gelatinase negative while Brevibacteria are gelatinase positive. I distinguished between the gram positive cocci by challenging them with the antibiotic bacitracin. Staphylococcus are resistant to bacitracin but Micrococcus are susceptible.

\section{Statistical analyses}

To calculate the similarity of the community of axillary microflora between male and female subjects I used the Jaccard Index as described below (Chao et al., 2005):

$$
\begin{gathered}
\qquad J=\frac{A}{A+B+C} \\
\text { A }=\text { the number of taxa shared between two samples } \\
\mathrm{B}=\text { the number of taxa unique to sample } 1 \\
\mathrm{C}=\text { the number of taxa unique to sample } 2
\end{gathered}
$$

Using an ANOVA, I analyzed the effect of microbial similarity, as well as women's menstrual cycle phase on their perception of the pleasantness, sexiness, and intensity of the men's body odor. Where significant differences were found, I used a Tukey's HSD test set to an experiment-wise error rate of 0.05 to determine exactly which means were significantly different. I also examined the data using ANOVA for evidence of age effects or effects of when, compared to other women, a woman was rating a shirt. For examples, did women who rated shirts on the first day perceive the odors differently than women who rated shirts on the last day. 
Additionally, I performed a Pearson pair-wise correlation test on the three

attractiveness ratings, pleasantness, sexiness, and intensity to determine if and how these measures were related.

\section{Results}

All three measures of attractiveness were significantly correlated with each other, however the strength of the relationships was insufficient $(\mathrm{r}<0.75)$ to warrant the creation of a composite measure. Pleasantness and sexiness showed the strongest correlation with $\mathrm{r}=0.68(\mathrm{p}<0.0001)$. Intensity was weakly negatively correlated with pleasantness, $r=-0.26(p<0.0001)$, and sexiness, $r=-0.11(p<0.0001)$. I therefore ran three separate analyses with each of the measures as a unique dependent variable.

Male age did not significantly affect how pleasant (ANOVA, $F=0.43, p=0.51$ ), how sexy (ANOVA, $F=0.23, p=0.64)$, or how intense (ANOVA, $F=0.47, p=0.49)$ women found the scent of men's shirts. Similarly, female age did not significantly affect how pleasant (ANOVA, $\mathrm{F}=0.51, \mathrm{p}=0.0 .48)$, how sexy (ANOVA, $\mathrm{F}=0.00, \mathrm{p}=0.96$ ), or how intense (ANOVA, $\mathrm{F}=0.09, \mathrm{p}=0.76$ ) women found the scent of men's shirts. Which day, relative to other women, a woman rated a shirt's odor also did not significantly affect how pleasant $($ ANOVA $F=0.05, p=0.82)$, how sexy $($ ANOVA, $F=$ $0.05 \mathrm{p}=0.82$ ) or how intense (ANOVA, $\mathrm{F}=0.77, \mathrm{p}=0.38$ ) she found the odor.

Similarity of the axillary microflora did not predict how pleasant women found the scent of men's body odor (ANOVA, $F=0.14, p=0.94)$. Women's menstrual cycle phase, however, did predict how pleasant they found the smell of each shirt (ANOVA, F $=8.28, \mathrm{p}<0.0001)$. In particular, women in the follicular and early luteal phase of their 
cycles found shirts to smell more pleasantly than women who were fertile, women who were in the mid to late luteal phase of their cycle, or women who were taking hormonal contraceptives (Fig. 11).

There was a significant interaction of axillary microflora similarity and menstrual cycle phase in determining how sexy women found the scent of men's body odor (ANOVA, $\mathrm{F}=3.13, \mathrm{p}<0.0001$ ). To determine where the differences lay, I ran a separate

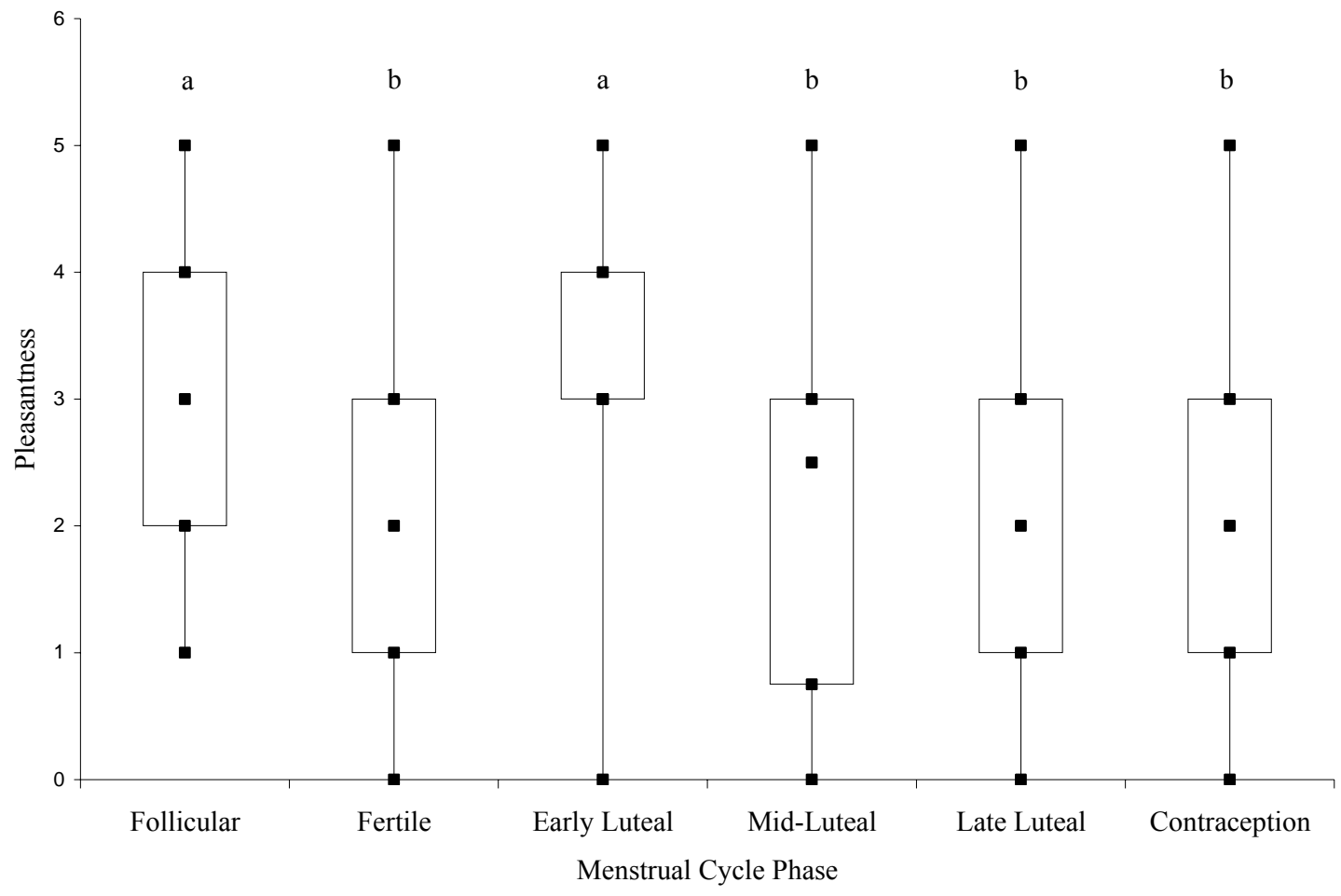

Figure 11. Women in the follicular and early luteal phases of their menstrual cycles found the scent of men's shirts more pleasant than women in any other phase of their cycle or women using hormonal contraceptive (ANOVA, $\mathrm{F}=8.28, \mathrm{p}<0.0001$ ). Boxes with different letters are significantly different at the 0.05 level. 
one-factor ANOVA on the effect of similarity for each level of axillary menstrual phase and used Tukey's HSD multiple comparison method with an experimentwise error rate set to $\mathrm{p}=0.008$ to control for the inflated Type I error.

I found that only women in the follicular phase of their menstrual cycles had a significantly different preference for the scent of men with varying degrees of similarity (ANOVA, $\mathrm{F}=6.11, \mathrm{p}=0.007$ ). These women preferred the scent of dissimilar men to the scent of similar men (Fig. 12). Women in every other phase of their cycles as well as women using hormonal birth control found the scent of men equally sexy, regardless of how similar these men were to themselves.

Similarity of the axillary microflora did not affect how intense women found the scent of men's body odor (ANOVA, $F=2.52, \mathrm{p}=0.06$ ). Women's menstrual cycle phase, however, did predict how intense they found the smell of each shirt (ANOVA, F = $30.86, \mathrm{p}<0.0001)$.Women in the early luteal phase of their menstrual cycles found the scent of men's body odor to be significantly weaker than did any other women. Women in the fertile and mid-late luteal phases of their menstrual cycles found the scent of men's body odor to be significantly stronger than any other women (Fig. 13). 


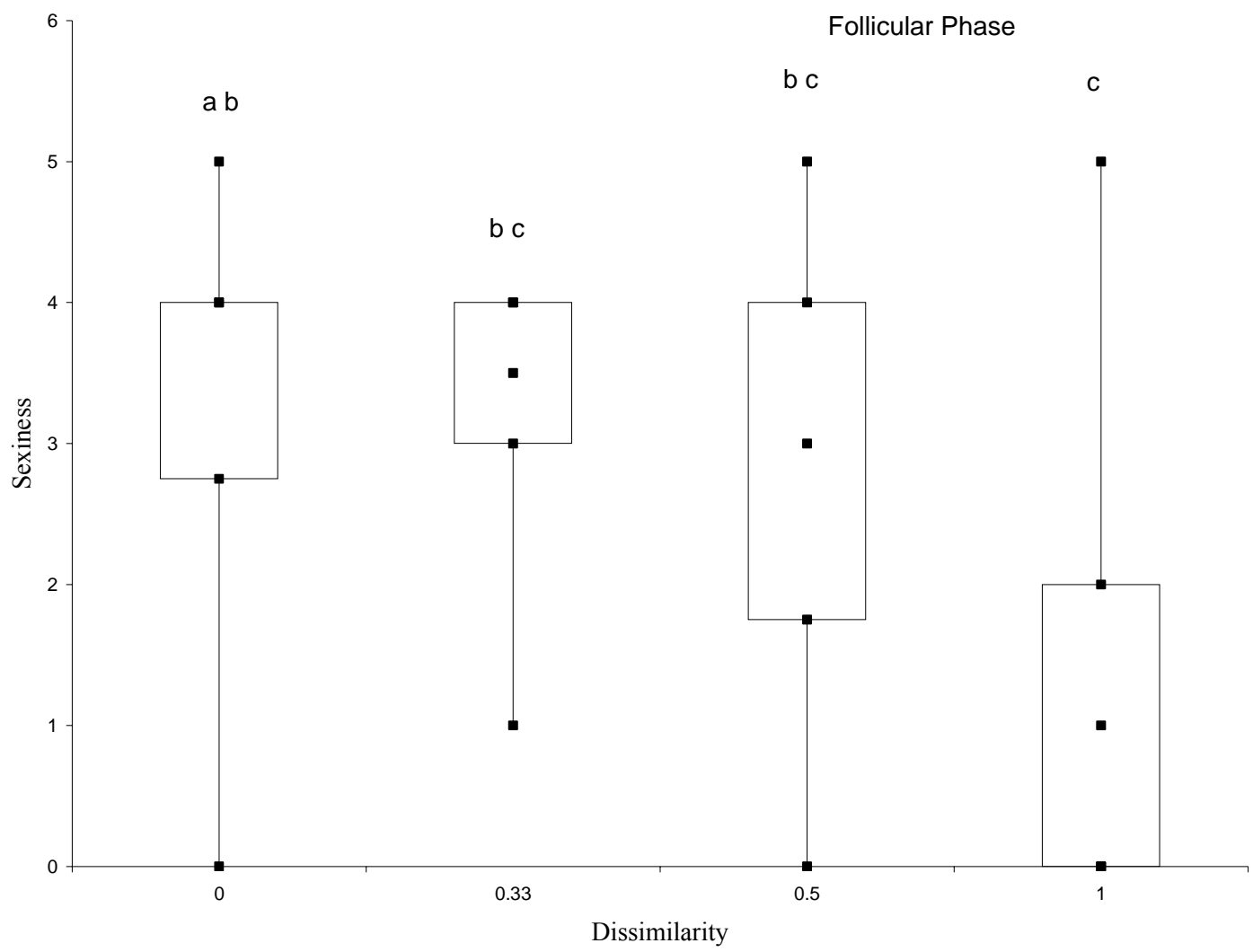

Figure 12. Women in the follicular phase of their menstrual cycles found the scent of completely dissimilar men to be significantly sexier than the scent of completely similar men. Boxes with different letters are significantly different at the 0.008 level. 


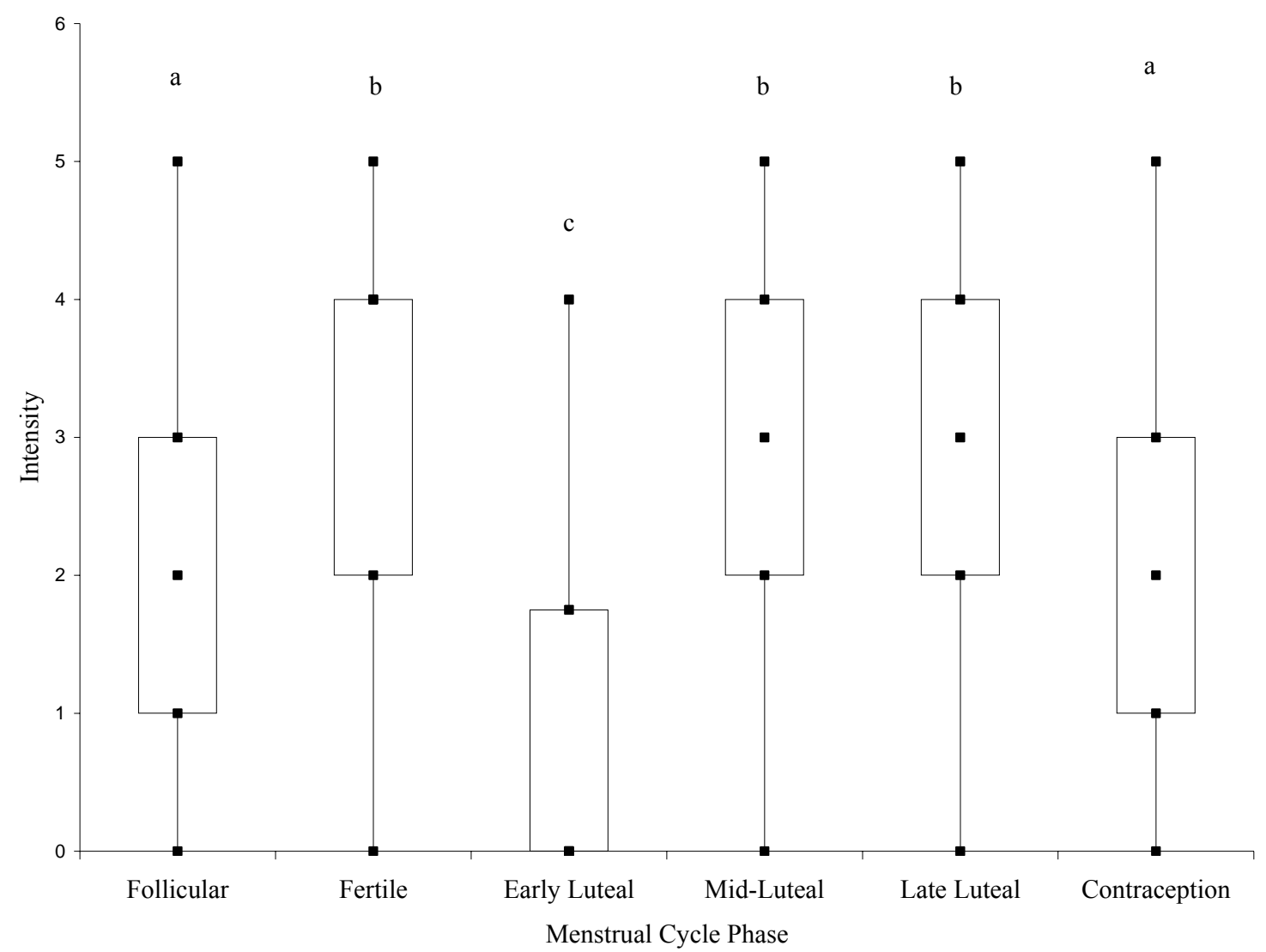

Figure 13. Women in the early luteal phase of their menstrual cycles found the scent of men's body odor to be significantly weaker than any other women. Women in the fertile and mid-late luteal phases of their menstrual cycles found the scent of men's body odor to be significantly stronger than any other women. Boxes with different letters are significantly different at the 0.05 level.

\section{Discussion}

The purpose of this study was to determine whether women prefer the odor of men who have a dissimilar community of axillary microflora than themselves and whether this preference was strongest among women who were most likely to be fertile at 
the time. The results of this study partially support this hypothesis. Some women did prefer the scent of men who had a dissimilar community of axillary microflora than themselves. However it was not the women in the fertile phase of their menstrual cycles, but rather women in the follicular phase who demonstrated this preference. Women in the fertile phase of their cycles showed no preference for men with dissimilar microflora compared with men who had similar microflora to themselves.

The commensal microflora hypothesis for MHC disassortative mating patterns suggests that MHC genes control the microflora which ultimately produce odor (Froebe et al., 1990;Natsch et al., 2003; Shelley et al., 1953;Zeng et al., 1992), and thus MHC genes may control odor. Although I did not test this hypothesis directly, if this hypothesis were true, then individuals should prefer the scent of others whose commensal microflora differ from their own. My results, therefore, provide indirect support for the commensal microflora hypothesis of MHC disassortative mating patterns. Future work should also determine MHC-type of individuals in addition to commensal microflora community composition and scent preferences in order to establish a more direct link.

As in my previous study (see Chapter 3), I again found that women in the follicular phase of their cycles found the scent of men's shirts to be more pleasant than other women. Perhaps the follicular phase is an important time for selecting mates that has been previously overlooked. By beginning the selection process prior to her fertile phase, she may be allowing herself more time for discrimination.

I also found that women in the early luteal phase of their cycles found men's scent to be more pleasant than did other women. However, women in the early luteal phase also deemed the smell of men's shirts to be weaker than did other women. Perhaps they 
found the scent of men's shirts so pleasant merely because their sense of smell was impaired relative to other women.

In this study, I again found interesting patterns of women's olfactory sensitivity. As in previous research (Doty et al., 1982; Herberhold et al., 1982) I found that women in the fertile and mid-late luteal phases of their cycles were most sensitive to odors. The dip in sensitivity in the early luteal phase, immediately following the fertile phase may be due to the low levels of circulating estrogen and progesterone at that point. More work needs to be done examining the effects of hormones and other neuromodulatory mechanisms involved in the menstrual cycle and how they affect olfactory acuity. In conclusion, this study has shown tentative support for the commensal microflora hypothesis of MHC disassortative mating patterns. Further work is needed to determine how directly commensal microflora composition is tied to MHC-type. In addition, it would be interesting to determine how cognizant women may be of what they are selecting. For example, women could be asked to rate how similar the odor of the shirt is to their own perceived body odor, the body odor of close kin, or the body odor of previous or current partners. 


\section{Chapter 5}

\section{SUMMARY AND FUTURE CONSIDERATIONS}

\section{General Summary}

The objective of my dissertation research was to determine the role of chemical signals in conveying information regarding an individual's health status and suitability as a mate in humans. Additionally I examined the role that commensal microflora play in this system. While studying the behavior of a species as complex and legally protected as our own offers many challenges, ultimately if we want to understand the ways in which natural selection has shaped our own behavior, we must undertake these challenges. Using humans, I was able to investigate the role that health plays in determining the chemical signals that we send as well as the role that chemical signals may play in mate attraction.

Several hypotheses have been suggested to explain how information regarding health status could be conveyed via body odor (Fig. 14). Illness could affect the compounds present in axillary secretions which bacteria act on, thus creating odor. This could happen in at least two ways: 1) the pathogen may release chemicals into the body which are directly secreted in the axilla and 2) the chemicals secreted by the pathogen may be picked up by MHC molecules (either class I or II) and carried to the axillary glands. Alternatively, or perhaps in addition, illness could affect the community of commensal bacteria living on the skin of the axillae. By changing this community, 


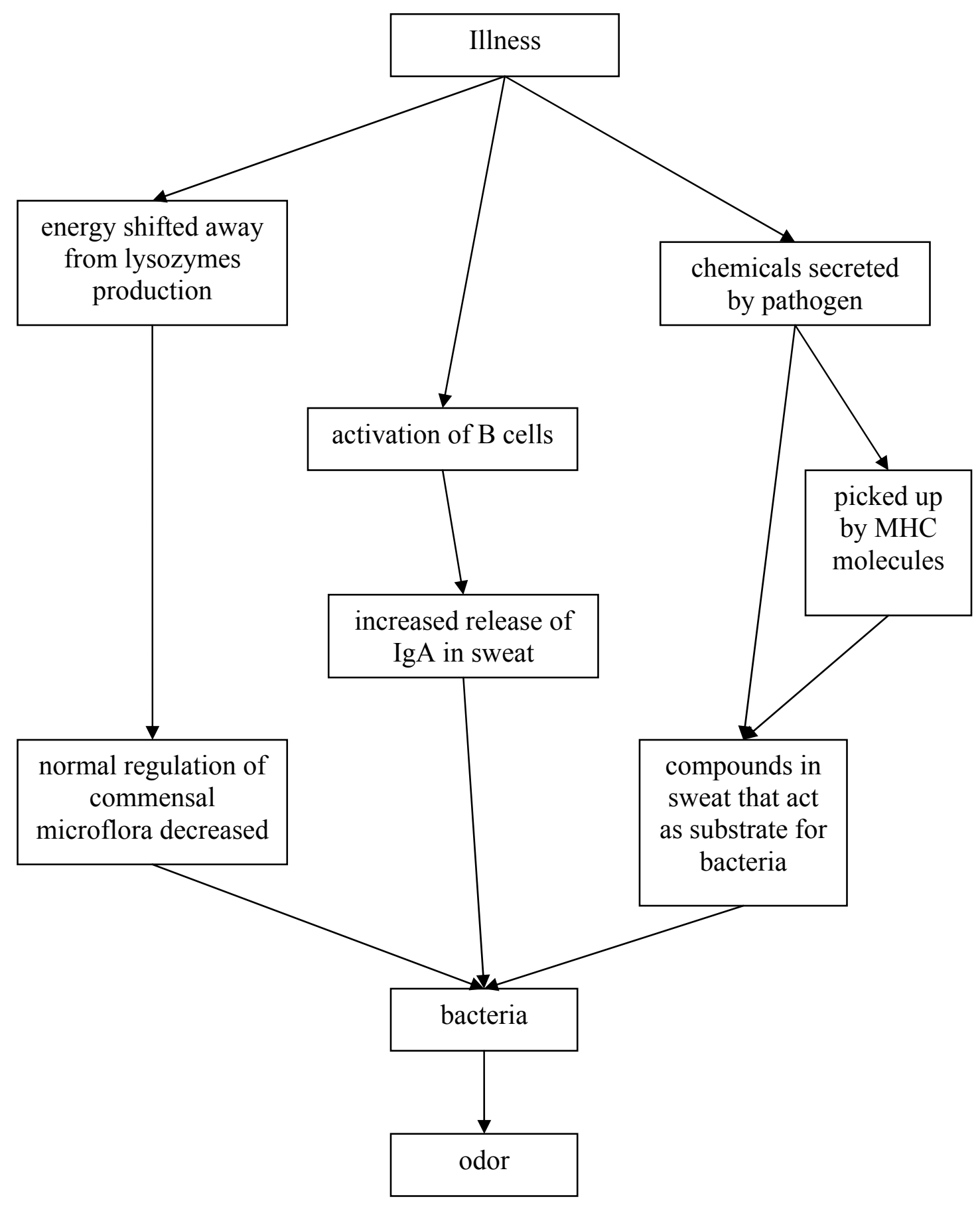

Figure 14. Proposed mechanisms that would lead from an illness to a change in body odor. 
illness could alter odor. Again, there are multiple pathways that could lead from illness to an alteration of commensal microflora. In response to a pathogen, B cells may be activated causing an increased production of antibodies. IgA antibodies, in particular, are secreted in sweat and could thus alter the community of microbes on the skin. Also, as the body shifts resources to specific immune responses in order to battle a specific pathogen, resources could be shifted away from non-specific immune systems. For example, energy could be shifted away from lysozyme production. Since lysozymes are normally secreted in sweat, they act as regulators of commensal microflora. Any shift away from this normal regulation could lead to an alteration of the community and thus an alteration of odor.

I found evidence that health can affect the composition of commensal microbes on the skin which are responsible for our body odor (Chapter 2 and Chapter 3). Both the richness of the microbes present (Chapter 2) and the presence of one particular group of microbes, the Micrococci (Chapter 3) are influenced by the health of their host.

The results from Chapter 2 demonstrate that both men and women experience alterations in the composition of their commensal microflora around times of illness. Individuals who had been ill experienced a decline in the richness of commensal microbes. This decline was not due to an overall decrease in the density of microbes however as both individuals who had not been sick and those who had maintained equally dense communities of commensal microbes. The results from Chapter 3 further elucidate the differences effected in the commensal microbe community by host illness. Men who were ill were significantly more likely to possess species of the genus Microccous amongst their commensal microbes than men who were healthy. This 
suggests that the decrease in community richness may be the result of Micrococcus species gaining a competitive advantage when the commensal community is disrupted. Since this group of microbes produces an odor that is more acidic than the odor typically associated with more Coryneform dominated microflora, this difference between healthy and ill men should result in a difference in the chemical signal being emitted.

However, if there is a difference in the odor of men who are ill, the research discussed in Chapter 3 suggests that women either are not sensitive to these alterations due to illness or due not prefer the one scent over the other. The primary illness afflicting subjects in my research was the common cold. It is possible that this illness is not severe enough to create much of a selective pressure on women. I would expect chemical signals to be more important not only in conveying information regarding more severe illnesses but also in conveying information of infection in the absence of visual signals. Many pathogens do not create visual signals of their presence until days, weeks, or even longer after the initial infection. In addition, symptoms may only appear during the initial infection, but then attenuate despite the persistence of the infection. In these cases, selection could well favor an individual who is able to find other cues, such as olfactory cues, to the presence of an infection.

Women, also, may be using olfactory cues for information gathering without necessarily making an immediate mate selection. If women are attempting to select longterm mates, or even just assessing potential future short-term mates, they may be gathering information without making an initial judgment. I would not expect that smelling an individual is ill once would send as strong a negative signal as detecting an odor of illness on the same person multiple times. Particularly in regards to common 
infections such as the cold, having a cold once does not indicate any particular weakness of the immune system. However, an individual who has frequent colds could be deemed as immunologically weak and an unsuitable mating partner.

Chemical signals have been suggested to carry not only information regarding current health status, but also information regarding genotype of one particular part of the immune system, the major histocompatibility complex (MHC). Again, several mechanisms have been suggested to explain how MHC molecules could influence body odor (Fig. 15). The evidence discussed in Chapter 1 suggests that two of these mechanisms, the MHC molecule hypothesis and the carrier hypothesis, are unlikely to be the cause of MHC-derived body odors. MHC-type could be influencing body odor by controlling the delivery of chemicals released from the axillary glands, as suggested by the peptide-microflora hypothesis. Or, MHC-type could be influencing body odor through its role in antibody formation. MHC class II molecules present antigens on sensitized B cells which attract helper $\mathrm{T}$ cells. When helper $\mathrm{T}$ cells activate the $\mathrm{B}$ cells, they produce plasma cells which in turn produce antibodies. The antibodies produced will be specific to the antigens that MHC molecules present. When IgA antibodies are produced in response to these antigens, they are secreted in the sweat and thus produce an immune response on the skin which will target certain bacteria and not others. In this way, MHC-type can influence which bacteria are available on the skin to produce odor. The results of Chapter 4 provide evidence that women, at least women in the follicular phase of their cycles, prefer the scent of men whose community of commensal microbes is entirely different from their own. This has interesting implications for 


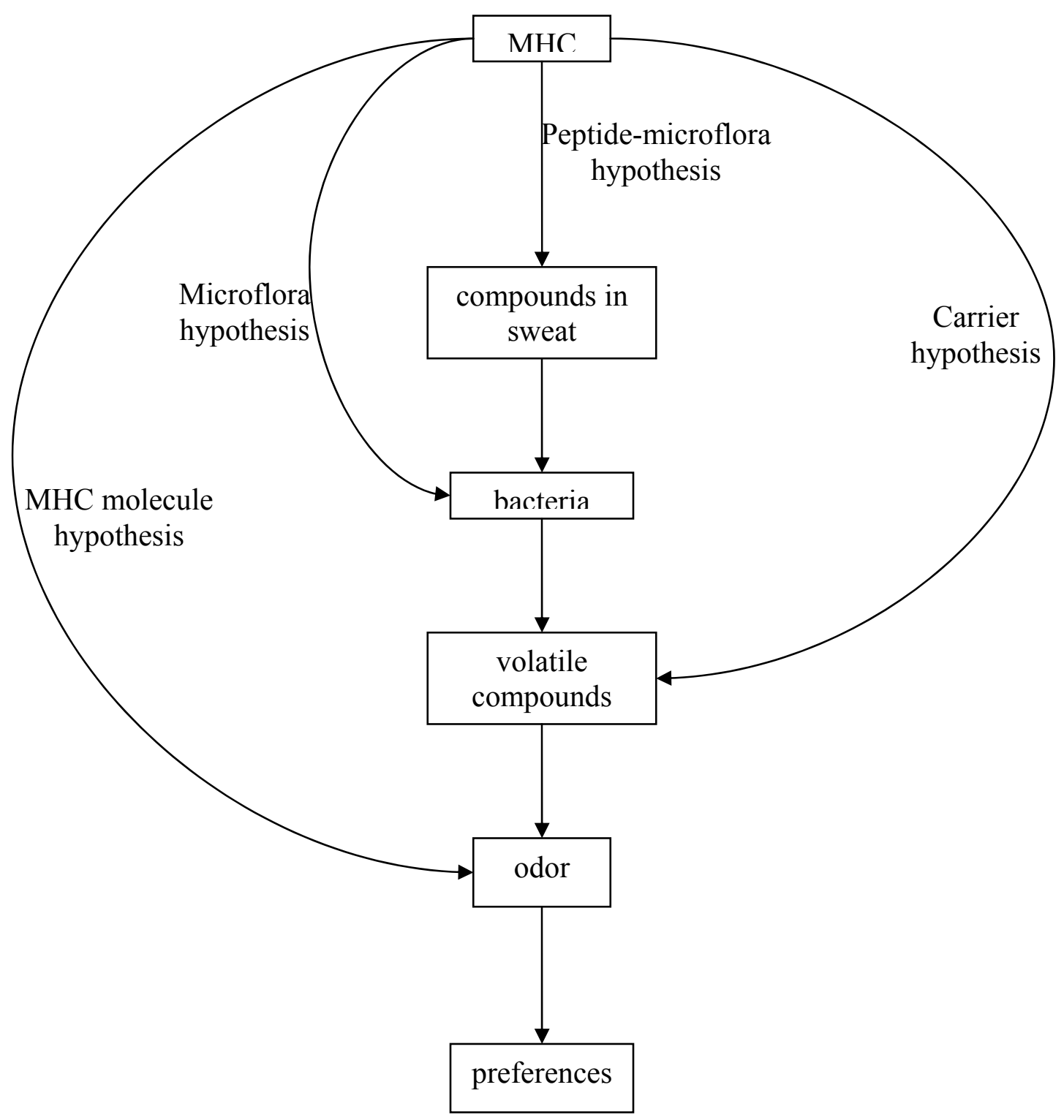

Figure 15. Proposed mechanisms that would lead from MHC-type to odor-type.

studies of disassortative mating patterns in humans, whether in regards to kin avoidance or pathogen-driven MHC disassortative mating. Since women prefer the odor of men with dissimilar commensal microbe communities, it is possible that they are using this dissimilarity as a cue for further, potentially genetic, dissimilarities. 
In addition to illuminating alterations in the community of commensal skin microbes due to health, my dissertation has provided a necessary first step for research into the role of health and commensal microbes in human mate selection. Previous research concerning chemical signals and mate selection in humans has failed to investigate mechanistic links. By examining the relationship between commensal microbes and scent preferences I have made the initial foray into connecting theories of what traits a woman should prefer and how information regarding those traits could be conveyed through body odor.

\section{Future Considerations}

In order to understand the dynamics of the relationship between health and commensal microbes, more work is needed to pinpoint how quickly the microflora are altered due to illness and how quickly the community recovers to its pre-illness state. This will involve sampling individuals more frequently than every 6 weeks and for a longer period of time than 3 months. In addition a broader sample of illnesses would allow a determination as to what kinds of illnesses lead to an alteration of the commensal microflora and how severe illnesses need to be to cause an alteration. For example brief, mild illnesses should have less influence on the commensal microflora than lengthy, severe illnesses. Furthermore, with greater access to health records, the effects of acute vs. chronic illnesses could be assessed. It is likely that chronic activation of the immune system would lead to greater alteration of the commensal microflora than infrequent activation. 
One limitation of my dissertation research was that I had to dependent on personal reports of an individual's health. Testing subjects directly for pathogen loads by assaying antibody production, or white blood cell counts, would allow for a more accurate identification of ill vs. healthy individuals.

Evolutionary theory suggests that women should be more concerned with detecting males who suffer from chronic or genetic diseases who likely would pass these poor genes onto their offspring or males who are highly contagious or suffering from severe illnesses so that they may avoid contracting the illness themselves. Numerous pathogens have a long incubation period during which the host is infected and potentially contagious but not exhibiting visible symptoms. Chemical signals of health status should be especially important during this time. As with mice who were able to detect individuals infected with mouse mammary tumor virus even when they were asymptomatic (Yamazaki et al., 2002), humans would benefit from early detection of illness in conspecifics. Future studies of scent preferences in humans should attempt to include a broader range of illnesses that may be of greater evolutionary significance.

Cross-cultural studies of olfactory signals in mate selection are also needed. We cannot say with authority what affect regular use of deodorant has on the axillary microflora and the chemical signals that these microflora produce. In addition, selective pressure to detect illness in potential mates should be greater in regions with greater pathogen loads than in regions with relatively mild pathogen loads. Cross-cultural studies would allow us to determine how important these factors are in traditional, as well as modern, societies. 
Future studies of disassortative mating patterns in humans should examine not only MHC-types but also commensal microflora. Clearly preferences for the scent of MHC-dissimilar individuals have been demonstrated (Thornhill et al., 2003;Wedekind \& Füri, 1997; Wedekind et al., 1995) but the mechanism linking MHC-type can no longer remain a black box. Commensal microflora have been suggested as the missing link to odor for both studies of MHC odor preferences (Penn \& Potts, 1998a) and symmetry odor preferences (Thornhill \& Gangestad, 1999). Including assays of commensal microflora is a relatively facile process which should be included in all future studies of body odor preferences.

My research has uncovered previously unseen preferences for odors by women in the follicular and early luteal phases of their cycles. Future research should pursue mechanisms that might account for this finding such as hormone levels and neuromodulatory mechanisms involved with the menstrual cycle. In addition, longitudinal studies of women's scent preferences are necessary to determine how labile this response is over the menstrual cycle.

Disease is a major selective factor in the lives of all organisms. The ability to detect and avoid unhealthy conspecifics, especially in a social species such as humans, is vital. In addition, avoiding potential mates who have demonstrated a susceptibility to disease is imperative in order to produce offspring with the best chances of survival possible. Commensal microflora provide a mechanism for detecting those who are currently ill because they are responsible for body odor and they are altered during illness. In addition, commensal microflora may provide a mechanism for detecting those individuals who carry genes for disease resistance. Chemical signals are a fascinating 
and potentially important aspect of social communication in humans. Historically the human ability to convey and detect information through chemical means has been largely ignored. The work described in my dissertation will add to our understanding of chemical signals in humans as well as our understanding of the relationship between ourselves and our commensal microbes. Additionally, the work described in this dissertation opens new doors for research into the mechanisms behind and evolutionary causes for chemical signals in our species. 


\section{REFERENCES}

Agosta, W. C. (1992). Chemical Communication: The Language of Pheromones Scientific American Library.

Alters, S. \& Alters, B. (2006). Biology: Understanding Life, 1st edition. New York: John Wiley \& Sons, Inc.

Apanius, V., Penn, D., Slev, P. R., Ruff, L. R., \& Potts, W. K. (1997). The nature of selection on the major histocompatibility complex. Critical Reviews in Immunology, 17, 179-224.

Brennan, P. A. \& Kendrick, K. M. (2006). Mammalian social odours: attraction and individual recognition. Philosophical Transactions of the Royal Society BBiological Sciences, 361, 2061-2078.

Brennan, P. A. \& Zufall, F. (2006). Pheromonal communication in vertebrates. Nature, $444,308-315$.

Brown, R. (1995). What is the role of the immune system in determining individually distinct body odours? International Journal of Immunopharmacology, 17, 655661.

Brown, R. E., Roser, B., \& Singh, P. B. (1989). Class I and class II regions of the major histocompatibility complex both contribute to individual odors in congenic inbred strains of rats. Behavior Genetics, 19, 659-674. 
Brown, R. E. \& Schellinck, H. M. (1992). Interactions among the MHC, diet and bacteria in the production of social odors in rodents. In R. L. Doty and D. MüllerSchwarze, (Eds.), Chemical Signals in Vertebrates VI 175-181. New York: Plenum Press.

Brown, R. E., Singh, P. B., \& Roser, B. (1987). The Major Histocompatibility Complex and the chemosensory recognition of individuality in rats. Physiology \& Behavior, 40, 65-73.

Chao, A., Chazdon, R. L., Colwell, R. K., \& Shen, T.-J. (2005). A new statistical approach for assessing similarity of species composition with incidence and abundance data. Ecology Letters, 8, 148-159.

Claus, R. \& Alsing, W. (1976). Occurrence of 5 $\alpha$-anrost-16-en-3-one, a boar pheromone, in man and its relationship to testosterone. Journal of Endocrinology, 68, 483-484.

Clayton, D. H. (1991). The influence of parasites on host sexual selection. Parasitology Today, 7, 329-334.

Curtis, V. \& Biran, A. (2001). Dirt, disgust and disease: is hygiene in our genes? Perspectives in Biology and Medicine, 44, 17-31.

Cutler, W. B., Preti, G., Krieger, A., Huggins, G. R., Garcia, C. R., \& Lawley, H. J. (1986). Human axillary secretions influence women's menstrual cycles: The role of donor extract from men. Hormones and Behavior, 20, 463-473.

Darwin, C. (1871). The descent of man, and selection in relation to sex. London: John Murray.

Doty, R. L. (1985). The primates III: humans. In R. E. Brown and D. W. Macdonald, (Eds.), Social Odours in Mammals. Oxford: Clarendon Press. 
Doty, R. L., Hall, J. W., Flickinger, G. L., \& Sondheimer, S. J. (1982). Cyclical changes in olfactory and auditory sensitivity during the menstrual cycle: no attenuation by oral contraceptive medication. In W. Breipohl, (Ed.) Olfaction and Endocrine Regulation 35-42. London: IRL Press Limited.

Doty, R. L., Orndorff, M. M., Leyden, J. J., \& Kligman, A. M. (1978). Communication of gender from human axillary odors: relationship to perceived intensity and hedonicity. Behavioral Biology, 23, 373-380.

Edman, D. C. \& Brooks, J. B. (1983). Gas-liquid chromatography-frequence pulsemodulated electron-capture detection in the diagnosis of infectious diseases. Journal of Chromatrography, 274, 1-25.

Falk, K., Rotzschke, O., Stevanovic, S., Jung, G., \& Rammensee, H.-G. (1991). Allelespecific motifs revealed by sequencing of self-peptides eluted from MHC molecules. Nature, 351, 290.

Ferreira-Poblete, A. (1997). The probability of conception on different days of the cycle with respect to ovulation: an overview. Advances in Contraception, 13, 83-95.

Ferstl, R., Eggert, F., Westphal, E., Zavazava, N., \& Muller-Ruchholtz, W. (1992). MHC-related odors in humans. In R. L. Doty and D. Müller-Schwarze, (Eds.), Chemical Signals in Vertebrates VI 205-211. New York: Plenum Press.

Folstad, I. \& Karter, A. J. (1992). Parasites, bright males, and the immunocompetence handicap. The American Naturalist, 139, 603-622.

Froebe, C., Simone, A., Chraig, A., \& Eigen, E. (1990). Axillary malodor production: A new mechanism. Journal of the Society of Cosmetic Chemists, 41, 173-185. 
Gangestad, S. W. \& Buss, D. M. (1993). Pathogen prevalence and human mate preferences. Ethology and Sociobiology, 14, 89-96.

Gilbert, A. N., Yamazaki, K., Beauchamp, G. K., \& Thomas, L. (1986). Olfactory discrimination of mouse strains (Mus musculus) and major histocompatibility types by humans (Homo sapiens). Journal of Comparative Psychology, 100, 262265.

Gotelli, N. J. \& Ellison, A. M. (2004). A primer of ecological statistics. Sunderland, MA: Sinauer Associates.

Grammer, K., Bernhard, F., \& Neave, N. (2005). Human pheromones and sexual attraction. European journal of obstetrics and gynecology and reproductive biology, 118, 135-142.

Grammer, K. \& Thornhill, R. (1994). Human (Homo sapiens) facial attractiveness and sexual selection: the role of symmetry and averageness. Journal of Comparative Psychology, 108, 233-242.

Hamilton, W. D. \& Zuk, M. (1982). Heritable true fitness and bright birds: a role for parasites? Science, 218, 384-387.

Hedrick, P. W. \& Black, F. L. (1997). HLA and mate selection: no evidence in South Amerindians. American Journal of Human Genetics, 61, 505-511.

Hepper, P. G. (1988). The discrimination of human odour by the dog. Perception, 17, $549-554$.

Herberhold, C., Genkin, H., Brändle, L. W., Leitner, H., \& Wöllmer, W. (1982). Olfactory threshold and hormone levels during the human menstrual cycle. In W. 
Breipohl, (Ed.) Olfaction and Endocrine Regulation 343-351. London: IRL Press Limited.

Ihara, Y., Aoki, K., Tokunaga, K., Takahashi, K., \& Juji, T. (2000). HLA and human mate choice: tests on Japanese couples. Anthopological Science, 108, 199-214.

Jackman, P. J. H. \& Noble, W. C. (1983). Normal axillary skin in various populations. Clinical and Experimental Dermatology, 8, 259-268.

Jacob, S., Garcia, S., Hayreh, D., \& McClintock, M. K. (2002a). Psychological effects of musky compounds: comparison of androstadienone with androstenol and muscone. Hormones and Behavior, 42, 274-283.

Jacob, S., McClintock, M. K., Zelano, B., \& Ober, C. (2002b). Paternally inherited HLA alleles are associated with women's choice of male odor. Nature Genetics, 30, $175-179$.

Kavaliers, M. \& Colwell, D. D. (1995a). Discrimination by female mice between the odours of parasitized and non-parasitized males. Proceedings of the Royal Society B: Biological Sciences, 261, 31-35.

Kavaliers, M. \& Colwell, D. D. (1995b). Odours of parasitized males induce aversive response in female mice. Animal Behaviour, 50, 1161-1169.

Kavaliers, M., Colwell, D. D., Braun, W. J., \& Choleris, E. (2003). Brief exposure to the odour of a parasitized male alters the subsequent mate odour responses of female mice. Animal Behaviour, 65, 59-68.

Kavaliers, M., Colwell, D. D., Ossenkopp, K. P., \& Perrot-Sinal, T. S. (1997). Altered responses to female odors in parasitized male mice: neuromodulatory mechanisms 
and relations to female choice. Behavioral Ecology and Sociobiology, 40, 373384.

Kohl, J. V., Atzmueller, M., Fink, B., \& Grammer, K. (2001). Human pheromones: integrating neuroendocrinology and ethology. Neuroendocrinology Letters, 22, 309-321.

Kuukasjarvi, S., Eriksson, C. J. P., Koskela, E., Mappes, T., Nissinen, K., \& Rantala, M. J. (2004). Attractiveness of women's body odors over the menstrual cycle: the role of oral contraceptives and receiver sex. Behavioral Ecology, 15, 579-584.

Labows, J. N. (1988). Odor detection, generation, and etiology in the axilla. In K. Laden and C. B. Felger, (Eds.), Antiperspirants and Deodorants 321-343. New York: Marcel Dekker, Inc.

Landry, C., Garant, D., Duchesne, P., \& Bernatchez, L. (2001). 'Good genes as heterozygosity': the major histocompatibility complex and mate choice in Atlantic salmon (Salmo salar). Proceedings of the Royal Society B: Biological Sciences, 268, 1279-1285.

Larson, E. L., McGinley, K. J., Foglia, A. R., Talbot, G. H., \& Leyden, J. J. (1986). Composition and antimicrobic resistance of skin flora in hospitalized and healthy adults. Journal of Clinical Microbiology, 23, 604-608.

Leyden, J. J., McGinley, K. J., Holzle, E., Labows, J. N., \& Kligman, A. M. (1981). The microbiology of the human axilla and its relationship to axillary odor. Journal of Investigative Dermatology, 77, 413-416.

Liddell, K. (1976). Smell as a diagnostic marker. Postgraduate Medical Journal, 52, 136138. 
Manning, C. J., Potts, W. K., Wakeland, E. K., \& Dewsbury, D. A. (1992). What's wrong with MHC mate choice experiments? In R. L. Doty and D. Müller-Schwarze, (Eds.), Chemical Signals in Vertebrates VI 229-235. New York: Plenum Press.

Martins, Y., Preti, G., Crabtree, C. R., Runyan, T., A. Vainius, A., \& Wysocki, C. J. (2005). Preference for human body odors is influenced by gender and sexual orientation. Psychological Science, 16, 694-701.

McLennan, D. A. \& Brooks, D. R. (1991). Parasites and sexual selection: a macroevolutionary perspective. Quarterly Review of Biology, 66, 255-286.

Møller, A. P. (1994). Sexual selection and the barn swallow. Oxford: Oxford University Press.

Møller, A. P. \& Swaddle, J. P. (1998). Asymmetry, Developmental Stability, and Evolution. Oxford: Oxford University Press.

Moore, J. (2002). Parasites and the behavior of animals. Oxford: Oxford University Press.

Natsch, A., Gfeller, H., Gygax, P., Schmid, J., \& Acuna, G. (2003). A specific bacterial aminoacylase cleaves odorant precursors secreted in the human axilla. Journal of Biological Chemistry, 278, 5718-5727.

Nesse, G. \& Williams, C. (1995). Evolution and healing. London: Weidenfeld \& Nicolson.

Ober, C., Weitkamp, L. R., Cox, N., Dytch, H., Kostyu, D., \& Elias, S. (1997). HLA and mate choice in humans. American Journal of Human Genetics, 61, 497-504.

Pearse-Pratt, R., Schellinck, H. M., Brown, R. E., \& Roser, B. (1992). Evolutionary and immunological implications of the role of the MHC in olfactory signalling. In R. 
L. Doty and D. Müller-Schwarze, (Eds.), Chemical Signals in Vertebrates VI 167-173. New York: Plenum Press.

Penn, D. \& Potts, W. (1998a). How do major histocompatibility complex genes influence odor and mating preferences? Advances in Immunology, 69, 411-436.

Penn, D. \& Potts, W. K. (1998b). Chemical signals and parasite-mediated sexual selection. Trends in Ecology \& Evolution, 13, 391-396.

Penn, D., Schneider, G., White, K., Slev, P., \& Potts, W. (1998). Influenza infection neutralizes the attractiveness of male odour to female mice (Mus musculus). Ethology, 104, 685.

Penn, D. J. \& Potts, W. K. (1999). The evolution of mating preferences and major histocompatibility complex genes. American Naturalist, 153, 146.

Pinker, S. (1998). How the mind works. Harmondsworth: Penguin.

Polak, M. \& Trivers, R. (1994). The science of symmetry in biology. Trends in Ecology \& Evolution, 9, 122-124.

Preti, G., Wysocki, C. J., Barnhart, K. T., Sondheimer, S. J., \& Leyden, J. J. (2003). Male axillary extracts contain pheromones that afect pulsatile secretion of luteinizing hormone and mood in women recipients. Biology of Reproduction, 68, 21072113.

Read, A. F. (1990). Parasites and the evolution of host sexual behavior. In C. J. Barnard and J. M. Behnke, (Eds.), Parasitism and host behaviour 117-157. London: Taylor \& Francis.

Rikowski, A. \& Grammer, K. (1999). Human body odour, symmetry and attractiveness. Proceedings of the Royal Society B: Biological Sciences, 266, 869-874. 
Russell, M. J. (1976). Human olfactory communication. Nature, 260, 520-522.

S. W. Gangestad, R. T. (1998). Menstrual cycle variation in women's preferences for the scent of symmetrical men. Proceedings of the Royal Society B: Biological Sciences, 265, 927-933.

Schellinck, H. M., Rooney, E., \& Brown, R. E. (1995). Odors of individuality of germfree mice are not discriminated by rats in a habituation- dishabituation procedure. Physiology \& Behavior, 57, 1005-1008.

Shelley, W. B. \& Hurley, H. J. J. (1952). Methods of exploring human apocrine sweat gland physiology. A.M.A. Archives of Dermatology and Syphilology, 66, 156161.

Shelley, W. B., Hurley, H. J. J., \& Nichols, A. C. (1953). Axillary odor: experimental study of the role of bacteria, apocrine sweat, and deodorants. Archives of Dermatology and Syphilology, 68, 430-446.

Singer, A. G., Beauchamp, G. K., \& Yamazaki, K. (1997). Volatile signals of the major histocompatibility complex in male mouse urine. Proceedings of the National Academy of Sciences, 94, 2210-2214.

Singer, A. G., Tsuchiya, H., Wellington, J. L., Beauchamp, G. K., \& Yamazaki, K. (1993). Chemistry of odortypes in mice: Fractionation and bioassay. Journal of Chemical Ecology, 19, 569-579.

Singh, D. \& Bronstad, P. M. (2001). Female body odour is a potential cue to ovulation. Proceedings of the Royal Society B: Biological Sciences, 268, 797-801.

Singh, P. B., Brown, R. E., \& Roser, B. (1987). MHC antigens in urine as olfactory recognition cues. Nature, 327, 161. 
Singh, P. B., Herbert, J., Roser, B., Arnott, L., Tucker, D. K., \& Brown, R. E. (1990). Rearing rats in a germ-free environment eliminates their odors of individuality. Journal of Chemical Ecology, 16, 1667-1682.

Spencer, N. A., McClintock, M. K., Sellergren, S. A., Bullivant, S., Jacob, S., \& Mennella, J. A. (2004). Social chemosignals from breastfeeding women increase sexual motivation. Hormones and Behavior, 46, 362-370.

Thaler, E. R. \& Hanson, C. W. (2005). Medical applications of electronic nose technology. Expert Review of Medical Devices, 2, 559-566.

Thorne, F., Neave, N., Scholey, A., Moss, M., \& Fink, B. (2002). Effects of putative male pheromones on female ratings of male attractiveness: Influence of oral contraceptives and the menstrual cycle. Neuroendocrinology Letters, 23, 291-297.

Thornhill, R. \& Gangestad, S. W. (1999). The scent of symmetry: a human sex pheromone that signals fitness? Evolution and Human Behavior, 20, 175-201.

Thornhill, R., Gangestad, S. W., \& Comer, R. (1995). Human female orgasm and mate fluctuating asymmetry. Animal Behaviour, 50, 1601-1615.

Thornhill, R., Gangestad, S. W., Miller, R., Scheyd, G., McCollough, J. K., \& Franklin, M. (2003). Major histocompatibility complex genes, symmetry, and body scent attractiveness in men and women. Behavioral Ecology, 14, 668-678.

Thornhill, R. \& Møller, A. P. (1997). Developmental stability, disease and medicine. Biological Reviews, 72, 497-548.

Tovée, M. J., Tasker, K., \& Benson, P. J. (2000). Is symmetry a visual cue to attractiveness in the human female body? Evolution and Human Behavior, 21, 191-200. 
Trivers, R. (1972). Parental investment and sexual selection. In B. Campbell, (Ed.) Sexual selection and the descent of man 1871-1971 136-179. Chicago: Aldine Publishing Company.

Vander, A. J., Sherman, J. H., \& Luciano, D. S. (1986). Human physiology: the mechanisms of body function, 4th edition. New York: McGraw-Hill.

Wedekind, C. \& Füri, S. (1997). Body odour preferences in men and women: do they aim for specific MHC combinations or simply heterozygosity? Proceedings of the Royal Society B: Biological Sciences, 264, 1471-1479.

Wedekind, C., Seebeck, T., Bettens, F., \& Paepke, A. J. (1995). MHC-dependent mate preferences in humans. Proceedings of the Royal Society B: Biological Sciences, $260,245-249$.

Wolfinger, R. \& Chang, M. (1995). Comparing the SAS GLM and MIXED procedures for repeated measures. In Proceedings of the 20th Annual SAS Users Group Conference 1-11. Cary, NC: SAS Institute Inc.

Wysocki, C. J. \& Preti, G. (2004). Facts, fallacies, fears, and frustrations with human pheromones. The Anatomical Record Part A: Discoveries in Molecular, Cellular, and Evolutionary Biology, 281A, 1201-1211.

Wysocki, C. J., Yamazaki, K., Curran, M., Wysocki, L. M., \& Beauchamp, G. K. (2004). Mice (Mus musculus) lacking a vomeronasal organ can discriminate MHCdetermined odortypes. Hormones and Behavior, 46, 241-246.

Yamazaki, K., Beauchamp, G. K., Imai, Y., Bard, J., Phelan, S. P., Thomas, L., \& Boyse, E. A. (1990). Odortypes determined by the major histocompatibility complex in germfree mice. Proceedings of the National Academy of Sciences, 87, 8413-8416. 
Yamazaki, K., Boyse, E. A., Bard, J., Curran, M., Kim, D., Ross, S. R., \& Beauchamp, G. K. (2002). Presence of mouse mammary tumor virus specifically alters the body odor of mice. Proceedings of the National Academy of Sciences, 99, 5612-5615.

Zahavi, A. (1975). Mate selection -- a selection for a handicap. Journal of Theoretical Biology, 53, 205-214.

Zahavi, A. (1977). The cost of honesty. Journal of Theoretical Biology, 67, 603-605.

Zala, S. M., Potts, W. K., \& Penn, D. J. (2004). Scent-marking displays provide honest signals of health and infection. Behavioral Ecology, 15, 338-344.

Zeng, C., Spielman, A. I., Vowels, B. R., Leyden, J. J., Biemann, K., \& Preti, G. (1996). A human axillary odorant is carried by apolipoprotein D. Proceedings of the National Academy of Sciences, 93, 6626-6630.

Zeng, X. N., Leyden, J. J., Brand, J. G., Spielman, A. I., McGinley, K. J., \& Preti, G. (1992). An investigation of human apocrine gland secretion for axillary odor precursors. Journal of Chemical Ecology, 18, 1039-1055.

Zeng, X. n., Leyden, J. J., Lawley, H. J., Sawano, K., Nohara, I., \& Preti, G. (1991). Analysis of characteristic odors from human male axillae. Journal of Chemical Ecology, 17, 1469-1492.

Zuk, M. (1992). The role of parasites in sexual selection: current evidence and future directions. Advances in the Study of Behavior, 21, 39-68.

Zuk, M., Thornhill, R., Ligon, J. D., \& Johnson, K. (1990). Parasites and mate choice in red jungle fowl. American Zoologist, 30, 235-244. 
APPENDIX 1

\section{Axillary Microflora Study A study to determine the effect of illness on axillary microflora}

Healthy volunteers are needed to take part in a research study

Volunteers will have their underarms swabbed 3 times at 6 week intervals

For more information, contact Amy Cavanaugh at 852-6731 or amy.cavanaugh@louisville.edu 


\section{Odor Preference Study}

Adult volunteers (age 18+) are needed to take part in a research study

Volunteers will be subject to the following procedures:

1) armpit swabbed with saline

2) wear a t-shirt for two nights OR

3) rate the odor of t-shirts worn by others

Volunteers will be compensated $\$ 10-\$ 20$ for their time and inconvenience.

For more information, contact Amy Cavanaugh at 852-6731 or amy.cavanaugh@louisville.edu 
APPENDIX 3

\section{Feeling Sick?}

\section{Want to earn some $\$ \$ ?$}

Adult men (age 18+) who are currently ill are needed to take part in a research study

Volunteers will be subject to the following procedures:

1) armpit swabbed with saline

2) wear a t-shirt for two nights

Volunteers will be compensated $\$ 20$ for their time and inconvenience.

For more information, contact Amy Cavanaugh at amy.cavanaugh@louisville.edu 


\section{APPENDIX 4}

T-shirt rating form

Date

Your Subject \#

Number on Bag

Rate the odor's pleasantness. $(0=$ unpleasant $5=$ very pleasant $)$

$\begin{array}{llllll}0 & 1 & 2 & 3 & 4 & 5\end{array}$

Rate the odor's sexiness. $(0=$ not at all sexy, $5=$ very sexy $)$

$\begin{array}{llllll}0 & 1 & 2 & 3 & 4 & 5\end{array}$

Rate the odor's intensity. ( $0=$ very weak, $5=$ very strong $)$

$\begin{array}{llllll}0 & 1 & 2 & 3 & 4 & 5\end{array}$

Do you smell any artificial odors? (i.e. smoke, cologne, deodorant, etc...)

Yes $\quad$ No

When you are finished with this shirt, please seal it back in its bag and move on to the next shirt. When you are done with all the shirts in this box, please return it to the counter and take another box. Please continue in this manner until you have smelled and rated all the shirts. Then bring your forms back to me. 


\title{
CURRICULUM VITAE
}

\author{
Amy M. Cavanaugh \\ Biology Department \\ University of Louisville \\ Louisville, KY 40292 \\ Phone: (502) 635-9284 \\ Email: amy.cavanaugh@louisville.edu
}

\begin{abstract}
Education:
2002 Drew University, B.A. in Biology, minor in French (Magna Cum Laude, Honors in Biology).

2005 University of Louisville, Masters of Science in Biology

2008 University of Louisville, $\mathrm{PhD}$ Biology program. Major advisor Lee

Dugatkin. Expected degree date 5/2008
\end{abstract}

\section{Research Experience}

2000 Drew International Seminar to the Galapagos Islands. Studied changes in abundance of endemic flora that Charles Darwin had collected.

2001-2002 Senior honors thesis. Examined effects of stream discontinuity on genetic variation in blacknose dace.

2002-2003 Studied individual variation in predator inspection behavior in zebrafish.

2003-2005 Studied female competition in a polygynous fish, Lamprologus ocellatus.

2005-2008 Studied interactions of human axillary microflora and body odor with respect to mate attraction.

Grants

2004-2005 Female competition and choice in a cichlid fish, Lamprologus ocellatus. 
Kentucky Academy of Sciences, Marcia Athey Fund.

2006-2007 A preliminary study to determine the effect of infection on the axillary microflora of humans. University of Louisville, Research Initiation Grant.

2007

The role of body odor in assessing health status of potential human mates. University of Louisville, Biology Graduate Student Association Research Grant.

\section{Publications}

Dugatkin LA, McCall MA, Gregg RG, Cavanaugh A, Christensen C, Unseld M. 2005. Zebrafish (Danio rerio) exhibit individual differences in risk-taking behavior during predator inspection. Ethology Ecology \& Evolution 17: 77-81.

Cavanaugh, A. 2007. Can they suffer? Trends in Ecology and Evolution 22: 633.

\section{Scientific Presentations}

Cavanaugh A. and Dugatkin LA. 2007. Effect of illness on axillary microflora. Midwest Ecology and Evolution Conference, Kent State University. Poster.

Cavanaugh A. and Dugatkin LA. 2007. Effect of illness on axillary microflora. Ecology, Evolution and Behavior Symposium, University of Kentucky. Oral presentation.

Cavanaugh A. and Dugatkin LA. 2007. Effect of illness on axillary microflora. Human Behavior and Evolution Conference, College of William \& Mary. Oral presentation.

Cavanaugh A. and Dugatkin LA. 2007. An opportunity for pathogen-mediated sexual selection in humans. Annual Meeting of the Animal Behavior Society, Burlington, VT.

\section{Teaching Experience:}

2000-2002 Teaching assistant, Drew University. Assisted with introductory ecology, microbiology, molecular biology, and cellular biology labs.

2004-Present Graduate teaching assistant at University of Louisville. Labs in anatomy and physiology, microbiology, general biology for non-majors, and introductory biology for majors. 
2006-Present Adjunct professor of Biology, Jefferson Community and Technical College.

$\mathrm{Lab}$ and lecture in introductory biology for non-majors.

Summer 2008 Adjunct professor of Biology, Spalding University

Evolutionary Biology, Human Biology.

\section{Awards}

2006 William T. Furnish Award for Excellence in Teaching of Biology

\section{University Service}

2003-2005 President, Biology Graduate Student Association

2007 Speaker Committee, Biology Graduate Student Association

\section{Professional Societies}

Animal Behavior Society

Human Behavior and Evolution Society 